\title{
Projected Health Financing Transitions: Timeline and Magnitude
}

\section{Rachel Silverman}

\begin{abstract}
In recent years, many global health institutions have adopted eligibility and transition frameworks for the countries they support, generating questions about how these frameworks apply in practice-and whether global health progress will be put at risk through premature or poorly planned transition processes. This paper builds on previous work in this space by mapping an indicative timeline of transition through 2040 across five global health financing mechanisms - Gavi, the Vaccine Alliance (Gavi); the Global Fund to Fight AIDS, Tuberculosis, and Malaria (the Global Fund); the World Bank's International Development Association (IDA); the Global Polio Eradication Initiative (GPEI); and the US President's Emergency Plan for AIDS Relief (PEPFAR) — with granularity by year and stage of transition. It contextualizes the magnitude of fiscal transition for each country with reference to overall government expenditure on health. Finally, it identifies countries and specific time periods of high transition risk based on cumulative fiscal impact. By 2040, it finds that Gavi and IDA will each see major transformations of their funding portfolios, while few large or aid-dependent countries will transition from Global Fund support. The countries in most fiscal jeopardy from anticipated transition are not those "transitioning" based on GDP per capita or disease burden, but instead those that are likely to be impacted by the near-term winddown of GPEI and reallocations of PEPFAR financing. A handful of countries face many major transitions within a very narrow time window_and the cumulative fiscal effect may be substantial, even if each individual transition should be manageable. Global health donors should build upon these results, working cooperatively at the country level, to ensure countries have a realistic understanding of transition processes to enable appropriate planning, budgeting, and prioritization.
\end{abstract}




\title{
Projected Health Financing Transitions: Timeline and Magnitude
}

\author{
Rachel Silverman \\ Center for Global Development
}

This work was conducted as part of the Working Group on the Future of Global Health Procurement, with support from the Bill \& Melinda Gates Foundation. I am grateful to CGD policy analyst Roxanne Oroxom, who conducted preliminary data analysis, and CGD research assistant Jessie $\mathrm{Lu}$, who helped prepare this paper for publication. Thank you to Amanda Glassman, Kalipso Chalkidou, Janeen Madan Keller, Melissa Malhame, Brenda Waning, Michael Borowitz, Carol D’Souza, Susie Nazzaro, Holly Greb, Aurelia Nguyen, Sarah Rose, and members of the Working Group on the Future of Global Health Procurement for helpful feedback and comments. All errors and omissions are my own.

The Center for Global Development is grateful for contributions from the Bill \& Melinda Gates Foundation in support of this work.

Rachel Silverman, 2018. "Projected Health Financing Transitions: Timeline and Magnitude.” CGD Working Paper 488. Washington, DC: Center for Global Development. https://www.cgdev.org/publication/projected-health-financing-transitions-timeline-andmagnitude

The data used in this paper is available here: https://www.cgdev.org/sites/default/files/ silverman-projected-health-financing-transitions-timeline.zip. More information on CGD's research data and code disclosure policy can be found here: www.cgdev.org/page/ research-data-and-code-disclosure.

Center for Global Development 2055 L Street NW Washington, DC 20036

202.416.4000

(f) 202.416 .4050

www.cgdev.org
The Center for Global Development works to reduce global poverty and improve lives through innovative economic research that drives better policy and practice by the world's top decision makers. Use and dissemination of this Working Paper is encouraged; however, reproduced copies may not be used for commercial purposes. Further usage is permitted under the terms of the Creative Commons License.

The views expressed in CGD Working Papers are those of the authors and should not be attributed to the board of directors, funders of the Center for Global Development, or the authors' respective organizations. 


\section{Contents}

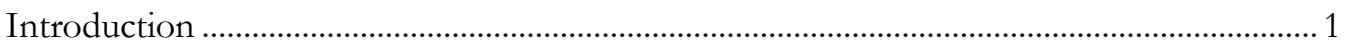

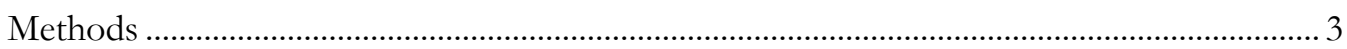

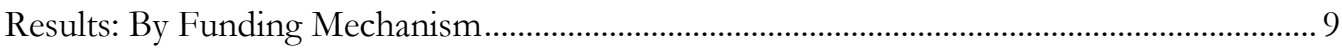

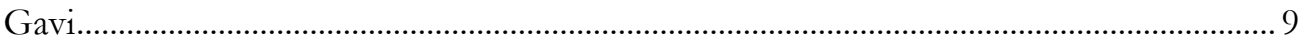

The Global Fund to Fight AIDS, Tuberculosis, and Malaria................................................11

International Development Association .............................................................................16

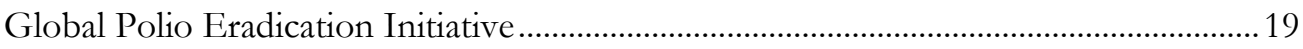

The President's Emergency Plan for AIDS Relief (PEPFAR) ...........................................20

Results: Transition Interactions, Sequencing, and Risk............................................................2

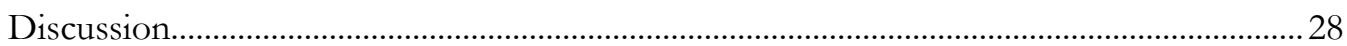

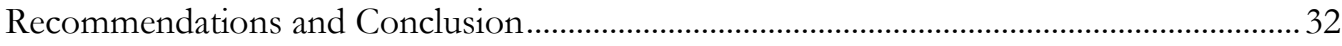

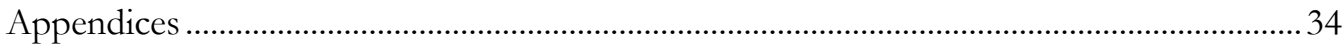




\section{Introduction}

It is a cliché in international development that organizations wish to "put themselves out of business." If international development institutions are successful, the countries they serve will grow and prosper, removing the need for continued assistance. Likewise, successful global health organizations will control and eradicate infectious global health threats, like smallpox historically, polio in the near future, and eventually the so-called "big three": HIV, tuberculosis (TB), and malaria.

In the real world, realpolitik and donor fatigue complicate this aspirational vision of transition based on our own collective success. Donor countries face ongoing pressure on their aid budgets, sparked originally by the financial crisis and kept alive by growing populist skepticism about the value and necessity of foreign aid given domestic needs. Press reports in donor countries contrast aid flows with symbols of the growing wealth in recipient countries, for example a space program in India. ${ }^{1}$ Global health institutions that depend on bilateral donor contributions implicitly understand that their funding will not last in perpetuity; they must offer an "end in sight" to antsy donors, while also reassuring donors and recipient countries alike that the "gains" will be sustained even after the funding stops. Recipient countries are told in vague terms that they must "prepare" for transition, but too often lack clarity on practical dimensions of that process, for example its timing, magnitude, or sequencing.

In response to these three forces-the ambition (and sometimes feasibility) to be a victim of one's own success, the recognition of real-world funding pressures, and the understanding that countries require greater predictability to successfully manage a transition process-in recent years many global health institutions have adopted eligibility and transition frameworks for the countries they support. These frameworks lay out criteria under which countries will lose eligibility for their support, and, typically, a gradual timeframe to phase out external financing. Other institutions lack explicit eligibility or transition frameworks yet are still expected to transition at least some countries from their assistance within the next decade. The question of how these transition processes will play out in practice-and whether global health progress will be put at risk through premature or poorly planned transition processes-has recently emerged as a hot topic in global health. The Global Fund to Fight AIDS, Tuberculosis, and Malaria (the Global Fund) has periodically updated its own transition projections for the period through $2025,{ }^{2}$ while civil society groups like Medecins

\footnotetext{
${ }^{1}$ Larisa Brown, "India boasts of satellite launch (as we hand them $f, 54 \mathrm{~m}$ of aid): MPs demand handouts are stopped as country reveals plans to explore space," Daily Mail, January 5, 2017, http://www.dailymail.co.uk/news/article-4089600/India-boasts-satellite-launch-hand-54m-aid-MPs-demandhandouts-stopped-country-reveals-plans-explore-space.html.

2 "Projected Transitions from Global Fund support by 2025 - projections by component," The Global Fund, March 2018, https://www.theglobalfund.org/media/5641/core projectedtransitionsby2025 list en.pdf? $\underline{\mathrm{u}}=636567241900000000$.
} 
Sans Frontiers, ${ }^{3}$ RESULTS, ${ }^{4}$ ACTION,${ }^{5}$ and Thinkwell ${ }^{6}$ have drawn from public sources to project and sound the alarm about imminent transitions for a subset of global health funding mechanisms, including "simultaneous transitions" from multiple mechanisms. Compared to countries that have previously transitioned from global health assistance, a recent working paper from Yamey et al. finds that countries expected to transition by 2020 "[seem] to have on average, lower per capita income, greater indebtedness, weaker capacity to efficiently use public resources, more limited and less effective health systems, weaker governance and public institutions, and greater inequality"7 — validating civil society concerns about preparedness for transition and the attendant risk.

This paper builds on previous work in this space with six innovations. First, it attempts to map out timeline of transition across five global health financing mechanisms-Gavi, The Vaccine Alliance (Gavi); the Global Fund; the World Bank's International Development Association (IDA); the Global Polio Eradication Initiative (GPEI); and the US President's Emergency Plan for AIDS Relief (PEPFAR) — with granularity by year and stage of transition. Second, it offers projections over a longer time horizon, extending out to 2040. Third, it contextualizes the fiscal magnitude of transition for each country with reference to overall estimated government expenditure on health. Four, it considers not just the fiscal impact of transition on countries but also on the global health institutions - that is, for the given timeframe, it quantifies the extent to which the transition approach will take the funding mechanisms toward "putting themselves out of business." Fifth, it identifies countries and specific time periods of high transition risk based not just on the number of transitions but on the cumulative fiscal impact. Finally, it provides a comprehensive online appendix (database) that can be used by funders and countries alike for a wide range of further analysis.

Importantly, this paper faces important limitations, which are discussed at length throughout but are sufficiently impactful to merit upfront discussion. First, data constraints and the inherent difficult of making long-term predictions means that the projections here should be understood as indicative estimates to help inform planning, not hard and fast predictions. Second, the paper focuses on the fiscal implications of global health transition; it does not cover the entirety of related programmatic, technical, and workforce issues, which are

\footnotetext{
${ }^{3}$ Nathalie Ernoult, "20 countries about to fall off Gavi funding 'cliff,' risking their ability to pay for life-saving vaccines for children long term,” MSF Access Campaign, November 28, 2017, https://www.msfaccess.org/aboutus/media-room/press-releases/20-countries-about-fall-Gavi-funding-_ $\% \mathrm{E} 2 \% 80 \% 98 \mathrm{cliff} \% \mathrm{E} 2 \% 80 \% 99$-riskingtheir.

${ }^{4}$ Laura Kerr and Leila Stennett, "A Balancing Act: risks and opportunities as polio and its funding disappears," Results, November 13, 2017, http://www.results.org.au/wp-content/uploads/2017/11/FINAL-Balancing-Actpdf.

${ }^{5}$ Heather Teixeira et al., "Progress in Peril? The Changing Landscape of Global Health Financing," Action Global Health Advocacy Partnership, September 19, 2017, http://www.action.org/uploads/documents/ 
themselves substantial and complex. Third, the fiscal implications are calculated based on government health expenditure at a single moment in time (the present); for longer-term projections especially, this "snapshot" approach will not reflect future changes in domestic spending on health, whether driven by economic growth or increased fiscal prioritization. Fourth, the paper projects a timeline of transition under current transition policies and with respect to current thresholds; in reality these are subject to frequent change and adjustment. Finally, it limits the scope of its analysis to a 10,000-foot view of changes in eligibility under current policy—not the entirety of co-financing requirements and transition-related changes at the country level. On a country-by-country basis, mechanisms such as the Global Fund are increasingly applying more aggressive co-financing requirements; mandating that countries assume fiscal responsibility for specific budget line items or commodities (for example, first-line tuberculosis drugs); and at times withholding funds if those requirements are not met. This paper traces changes in co-financing policy that occur due to progression through the stages of an explicit transition policy, but not changes in co-financing that are negotiated at the individual country level. (These issues are addressed in additional depth in the discussion section). As a result, the findings of this paper may underestimate the total impact of transition-related policies and are best understood in conjunction with in-depth country case studies, for example work currently underway by Thinkwell.

This paper proceeds as follows. I first describe the methods and data sources used to construct my indicative projections, including a catalogue of transition policies for Gavi, the Global Fund, and IDA. I then individually map anticipated transitions for each of three aforementioned aid mechanisms, plus PEPFAR and GPEI. Next, I consider the cumulative effect of anticipated transitions at the country level, identifying 11 countries at high fiscal risk from transition and another 10 countries at moderate risk from transition during the period of analysis. I conclude by discussing the implications for each funding mechanism, for recipient countries, and for the bilateral donors that collectively govern the entire set of global health institutions.

\section{Methods}

I first identified official eligibility and transition policies for the three largest global health financing mechanisms with explicit eligibility policies - Gavi; 8 the Global Fund to Fight AIDS, Tuberculosis, and Malaria (The Global Fund); ${ }^{9}$ and the World Bank's International Development Association (IDA) ${ }^{10}$ — and extracted all criteria and data requirements used by those institutions to determine a country's eligibility and co-financing requirements.

\footnotetext{
8 "Eligibility and Transition Policy," Gavi, June 2015, http://www.Gavi.org/library/Gavidocuments/policies/Gavi-eligibility-and-transition-policy/.

9 "The Global Fund Sustainability, Transition and Co-financing Policy," The Global Fund, May 2018, https://www.theglobalfund.org/media/7443/core eligibility policy en.pdf?u $=636635807340000000$; revised from previous version, April 2016, https://www.theglobalfund.org/media/4221/bm35 04sustainabilitytransitionandcofinancing_policy en.pdf; "The Global Fund Eligibility Policy," The Global Fund, April 2016, https://www.theglobalfund.org/media/4227/bm35 06-eligibility policy en.pdf.

10 "IDA Eligibility, Terms, and Graduation Policies," International Development Association, World Bank, January 2001, http://siteresources.worldbank.org/IDA/Resources/Seminar\%20PDFs/ida\%20eligibility.pdf.
} 
Once I had extracted the co-financing and eligibility policies, I set about collecting and collating the requisite data to replicate their eligibility processes and roughly project country eligibility into the future. A full list of data sources is presented in Table 1, and a set of spreadsheets with the full dataset is available as an online appendix. A summary of the three eligibility policies is presented in Table 2 .

The International Monetary Fund (IMF) provides data on current and projected levels of GDP per capita (in current prices). However, the IMF's growth projections have three weaknesses for this analysis. First, the projections only extend to 2022, and this analysis covers the period up to 2040. Second, the IMF only projects GDP per capita-not GNI per capita, which is formally used as the eligibility criterion by all three financing mechanisms. Third, the IMF did not include data for several aid-eligible countries. ${ }^{11}$

To address these limitations, I took the following steps. First, I decided to use GDP per capita in lieu of GNI per capita, understanding that doing so might introduce some minor errors. A comparative analysis of GNI per capita versus GDP per capita for 2016 in the relevant set of countries suggests that most differences are relatively minor; on average, GNI per capita deviated from GDP per capita by about 7 percent, with mixed directionality, although there were some notable outliers (see Appendix 1).

Second, data for 2015-2022, downloaded in August 2017, were run through Excel's FORECAST function to obtain predicated values for 2015-2040.12 Essentially, this assumes constant growth across the entirety of the analysis period; of course, this is unlikely to perfectly reflect reality, but creates a basis for indicative transition timelines. In a few cases, this approach created problematic results, particularly for the small subset of countries with projected economic contractions between now and 2022. For those countries, I manually changed the projections to assume constant GDP per capita past the end of the IMF projections. ${ }^{13}$ Third, I extrapolated future GDP per capita for Pakistan-a large and important health aid recipient with no IMF projections_-using reported World Bank GDP per capita in the period between 2015 and 2016. Fourth, I used the GDP per capita estimates (vis-à-vis current World Bank thresholds) to calculate country income groups, where necessary.

\footnotetext{
11 ODA eligible countries with missing IMF projection data included the Cook Islands, Cuba, Egypt, Montserrat, Niue, North Korea, Pakistan, Somalia, St. Helena, Syria, and the West Bank/Gaza. With the exception of Pakistan, these countries are excluded from this analysis.

12 "World Economic Outlook Database," World Economic and Financial Surveys, International Monetary Fund, 2017, https://www.imf.org/external/pubs/ft/weo/2017/02/weodata/index.aspx.

13 These countries include Ecuador, Equatorial Guinea, Haiti, Puerto Rico, South Sudan, Suriname, and Venezuela.
} 
Table 1. Data Sources for Analysis

\section{Variable Data Source(s)}

GDP per capita

Basic linear projections to 2040 based on projections through 2022 from the IMF World Economic Outlook, 2017

Country income category

Calculated by author based on GDP per capita projections, World Bank category thresholds ${ }^{14}$

List of currently eligible countries, Global Fund

2017 eligibility list ${ }^{15}$

List of current eligibility status for Gavi 2017 "countries eligible for support," 16 internet archives for countries previous years' status

List of currently eligible countries, IDA World Bank borrowing countries, $2018^{17}$

Disease burden for HIV, TB, and Malaria Global Fund 2017 eligibility list ${ }^{15}$ above15

Small Island Status World Bank borrowing countries, 201817

Membership in OECD/DAC DAC members ${ }^{18}$; DAC List of ODA Recipients Effective for reporting on 2014, 2015, 2016 and 2017 flows ${ }^{19}$

Malaria-Free Status Countries that have been certified by WHO as malaria-free or added to the supplementary list of countries where malaria never existed or disappeared without specific measures, $2012^{20}$

\footnotetext{
14 “World Bank Country and Lending Groups," World Bank, 2018, https://datahelpdesk.worldbank.org/ knowledgebase/articles/906519-world-bank-country-and-lending-groups. 15 “Eligibility List 2017," The Global Fund, 24 October 2016, https://www.theglobalfund.org/media/ $\underline{5601 / \text { core eligiblecountries } 2017 \text { list en.pdf?u }=636488964420000000 .}$.

16 "Countries eligible for support," Gavi, 2017, https://www.Gavi.org/support/sustainability/countries-eligiblefor-support/.

17 “Borrowing Countries," International Development Association, World Bank, http://ida.worldbank.org/about/borrowing-countries. 18 "DAC members," OECD, 2018, http://www.oecd.org/dac/dacmembers.htm.

19 "DAC List of ODA Recipients," OECD, http://www.oecd.org/dac/financing-sustainabledevelopment/development-finance-standards/DAC List ODA Recipients2014to2017 flows En.pdf. 20 “World Malaria Report 2012," World Health Organization, 2012: 67-69, http://www.who.int/malaria/areas/elimination/wmr-2012-supplementary-list.pdf.
} 
Table 2. Summary of Eligibility and Transition Policies

\begin{tabular}{|c|c|c|c|}
\hline & Gavi & The Global Fund (Revised May 2018) & IDA \\
\hline $\begin{array}{l}\text { Summary of } \\
\text { eligibility } \\
\text { policy }\end{array}$ & $\begin{array}{l}\text { - Countries below LIC } \\
\text { threshold: eligible, in “initial } \\
\text { self-financing," co-financing } \\
\text { at } \$ .20 \text { per dose } \\
\text { - Countries above LIC } \\
\text { threshold, below Gavi GNI } \\
\text { per capita threshold ( } \$ 1,580 \\
\text { as of 2018): eligible in } \\
\text { "preparatory transition," co- } \\
\text { financing increases by } 15 \% \\
\text { per year } \\
\text { Countries with GNI per } \\
\text { capita, averaged over } \\
\text { previous three years, above } \\
\text { threshold: enter five-year } \\
\text { "accelerated transition" } \\
\text { period in which funding } \\
\text { phases out } \\
\text { After end of five-year } \\
\text { "accelerated transition" } \\
\text { period, countries become } \\
\text { fully self-financing }\end{array}$ & $\begin{array}{l}\text { - Eligibility determined by disease component (HIV, TB, Malaria) } \\
\text { - Income category determined by three-year rolling average of GNI per capita vis-à- } \\
\text { vis World Bank thresholds } \\
\text { - LIC: eligible for all components; to access co-financing incentive (at least } 15 \% \text { of } \\
\text { - } \text { allocation), must increase co-financing by at least } 50 \% \text { of incentive amount } \\
\text { - allocation), must increase co-financing by at least } 100 \% \text { of incentive amount } \\
\text { - UMICs: eligible for components where disease burden is "high"; to access co- } \\
\text { financing incentive (at least } 15 \% \text { of allocation), must increase co-financing by at } \\
\text { - least } 100 \% \text { of incentive amount } \\
\text { - If a UMIC becomes ineligible based on disease burden, it may still receive an } \\
\text { allocation for a single three-year "transition" period. } \\
\text { HICs and members of the OECD's Development Assistance Committee: ineligible } \\
\text { Exceptions: } \\
\text { - Malaria-free countries are not eligible for malaria grants } \\
\text { - UMICs who are members of the G20 and were in eligible under previous policy } \\
\text { remain ineligible except via NGO rule (below) } \\
\text { Exceptions possible for "challenging operating environments" } \\
\text { Countries that are not listed as ODA-eligible by the Development Assistance } \\
\text { Committee cannot receive HIV funding unless there are "demonstrated barriers to } \\
\text { providing funding for interventions for key populations, as supported by the } \\
\text { country's epidemiology," in which case only NGOs can receive funding }\end{array}$ & 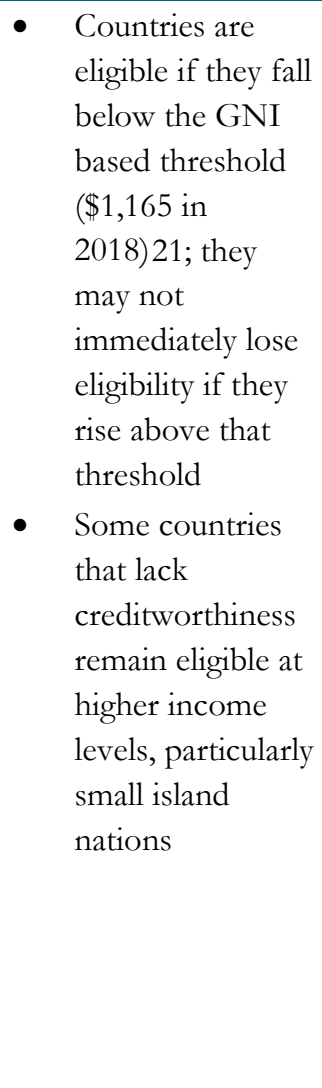 \\
\hline $\begin{array}{l}\text { Full list of } \\
\text { relevant } \\
\text { variables for } \\
\text { determining } \\
\text { eligibility }\end{array}$ & $\begin{array}{l}\text { - GNI per capita over } \\
\text { previous three-year period }\end{array}$ & $\begin{array}{l}\text { - } \text { GNI per capita over previous three-year period } \\
\text { - } \text { G20 membership } \\
\text { - } \text { Disease burden for HIV, TB, and malaria; } \\
\text { - } \\
\text { - } \\
\text { - } \\
\text { - Memall island nation status } \\
\text { Malia elimination status }\end{array}$ & $\begin{array}{l}\text { - } \text { GNI per capita } \\
\text { - } \quad \text { Small island } \\
\text { nation status }\end{array}$ \\
\hline
\end{tabular}

21 “Borrowing Countries," International Development Association, World Bank, 2018, http://ida.worldbank.org/about/borrowing-countries. 
A second issue related to projections of future disease burden-an important input for determining Global Fund eligibility. Most of this analysis was conducted in January 2018, prior to the Global Fund's most recent revision of its eligibility and transition policy. Under the previous policy, disease burden was categorized into five levels, from extreme to severe, high, moderate, and low (see Appendix 2). As I was unable to obtain reliable modelled projections, I projected transitions under two scenarios: (1) a status quo scenario, implying no change in disease burden for HIV, malaria, or tuberculosis by 2040; and (2) a universal progress scenario, where every country progressed by a single disease category (e.g. "extreme" to "severe," or "moderate" to "low") from baseline (2017) to 2025. Under the most recent revision to the eligibility policy, the Global Fund has streamlined its disease burden categories to "high" (comprising the previous extreme, severe, and high categories) and "not high" (comprising the previous moderate and low categories) - the only distinction with implications for eligibility under the new policy. The prior analysis is still applicable, as those countries previously categorized as "high" disease burden are the only countries where a reduction to "not high," and therefore to ineligibility for UMICs, is plausible within this timeframe.

Using this dataset, I calculated eligibility, by year, for every country between 2015 and 2040 for each of the three mechanisms. I then cross-checked my results against the most recent official eligibility lists for Gavi, the Global Fund, and IDA; where my results differed from actual current eligibility, I manually altered the results to reflect actual current eligibility. (In practice, differences were minor.) In some cases, a country was technically eligible for Global Fund support but had not received an allocation for the 2017-2019 cycle; in such cases, I counted the country as "ineligible" for the purposes of this analysis.

To paint a more complete picture of the overall funding landscape, I also wished to include information on a few funding mechanisms with less formal eligibility policies, but where funding changes over the coming years may nonetheless have dramatic fiscal impacts at the country level. PEPFAR is the largest single provider of development assistance for health in the world, with a budget of $\$ 5.2$ billion in bilateral funding for FY2016. ${ }^{22}$ PEPFAR does not have a formal transition policy, and it is difficult to project if and when major funding changes will occur. However, PEPFAR recently announced a policy of "acceleration" for a subset of just 13 countries; ${ }^{23}$ given the stagnant PEPFAR budget, this may imply a forthcoming decrease in funding for the remainder of countries that currently receive PEPFAR support. ${ }^{24}$ In addition, the GPEI provides intensive support to a subset of 16 priority countries but is expected to rapidly ramp down its operations over the next few years. I therefore include all available data on countries that might be impacted by these potential changes. ${ }^{25}$

\footnotetext{
22 “PEFAR Funding," PEPFAR, https://www.pepfar.gov/documents/organization/252516.pdf.

23 "Strategy for Accelerating HIV/AIDS Epidemic Control (2017-2020)," PEPFAR, 2017, https://www.pepfar.gov/documents/organization/274400.pdf.

24 PEPFAR financing data for 2016 (most recent year available) extracted from "PEPFAR Expenditures by Cost Category, 2012-2016," available from pepfar.gov.

25 GPEI financing data for 2017 extracted from "The End of the Beginning," Global Polio Eradication Programme, July 2017, http://polioeradication.org/wp-content/uploads/2017/07/TIMB Report-no1_Jul2017_EN.pdf.
} 
To understand the potential fiscal magnitude of these transitions, where possible I also extracted data on total funding for the most recent year available. For Gavi, I extracted data on total disbursements in 2017 for each country. ${ }^{26}$ For the Global Fund, I extracted each country's total allocation for each disease component for the 2017-2019 allocation cycle, ${ }^{27}$ and divided by three to annualize the result. For PEPFAR, I used disbursement data by country for 2016. ${ }^{28}$ Finally, I extracted 2017 expenditure for the 16 priority countries of the GPEI. ${ }^{29}$ I was unable to identify suitable data for IDA, as its support extends across sectors and annualized, health-specific expenditure is difficult to isolate.

As a final step, I investigated the rough fiscal impact of projected transition by comparing the magnitude of total funding from each mechanism to estimated total domestic government general health expenditure (GGHE-D) for 2015 (the most recent available year), calculated by multiplying GDP (current \$US) times domestic general government health expenditure as a percentage of GDP. ${ }^{30}$ This figure does not include donor or private expenditure on health, and thus does account for all resources available to the health sector. Nonetheless, it is a useful metric to contextualize the fiscal impact of transition, as it provides an indicative measure of a government's ability to absorb specific expenses that will no longer be covered by external donors. The lack of available data for more recent years unfortunately means that the analysis compares 2016 or 2017 disbursements to 2015 health expenditure, an imperfect reference point; again, these estimates are merely indicative, given this and the many other limitations discussed above.

Following the completion of this analysis, the Global Fund slightly updated its eligibility policy; the revised policy is described in Table 2. The updated policy had two major changes with implications for the results of this analysis. First, it removed a provision that would have made G20 countries, including India and Indonesia, ineligible for most support once they achieved upper-middle-income income status. Second, it changed the criteria for determining whether a country has a "high" or "not high" disease burden for tuberculosis. (Other disease areas were streamlined into these two categories, but the criteria were unchanged). The Secretariat suggests that seven countries may become newly or re-eligible

\footnotetext{
26 "Disbursements and commitments," Gavi, http://www.Gavi.org/country/all-countries-commitments-anddisbursements/.

27 "Global Fund Allocations for 2017-2019 Allocation Period," The Global Fund,

https://www.theglobalfund.org/media/4788/fundingmodel allocations20172019 table en.xlsx?u $=636487639020000000$.

${ }^{28}$ Downloaded on 15 March 2018 from "Planned funding, FY 2016," Dashboards, PEPFAR, https://data.pepfar.net/country/funding? country=Kenya\&year=2016.

29 "The End of the Beginning," Global Polio Eradication Programme, July 2017, http://polioeradication.org/wpcontent/uploads/2017/07/TIMB Report-no1 Jul2017 EN.pdf.

${ }^{30}$ Domestic government health spending from "Global Health Expenditure Database," World Health Organization, http://apps.who.int/nha/database. GDP data from "World Bank Databank," World Bank, https://data.worldbank.org/. 2015 GDP data used except for Cuba, Djibouti, and South Sudan (2014 data used); and Eritrea (2011 data used). Mozambique's reported level of GGHE-D for 2015 was far lower than the previous two years, and in general fluctuated dramatically from year to year. After consulting publicly available documents on Mozambique's level of government health expenditure (see: https://www.unicef.org/esaro/UNICEF Mozambique _- 2017 _- Health Budget Brief.pdf) I adjusted GGHE-D to reflect the average over the previous three-year period (2013-2015).
} 
for tuberculosis funding under the revised criteria. ${ }^{31}$ I manually updated the results to reflect the new policy; however, the underlying database was constructed based on the previous eligibility criteria.

\section{Results: By Funding Mechanism}

\section{Gavi}

A full list of projected transitions between 2015 and 2040 is presented in Table 3, ranked by the relative fiscal impact of Gavi disbursements (2017) as a percentage of total government health expenditure, estimated using 2015 data. The list includes countries that will fully transition from Gavi support by 2040 and those that will enter accelerated transition during that period; it excludes countries that will enter preparatory transition. Appendix 3 ranks countries by the absolute magnitude of Gavi support (disbursements) in 2017.

In Table 3, each country is represented by one row; each year between 2015 and 2040 is represented by one column. Green "E" squares represent periods during which a country is eligible to apply for new Gavi support and subject to a "Initial Co-financing" requirement of $\$ .20$ per dose. Yellow "P" squares represent periods during which a country is eligible to apply for new Gavi support but expected to enter the "Preparatory Transition" phase, requiring 15 percent annual increases in co-financing. Orange " $\mathrm{A}$ " squares represent the fiveyear "Accelerated Transition" phase; during this phase co-financing requirements rapidly increase, culminating in the termination of Gavi support. After the Accelerated Transition phase, the red "G" squares indicate that the country has fully graduated-referred to as "Fully Self-Financing" in Gavi parlance.

${ }^{31}$ Dominican Republic, Ecuador, Fiji, Iraq, Panama, Suriname, and Turkmenistan. See "Revised Eligibility Policy," 39th Board Meeting, The Global Fund to Fight AIDS, Tuberculosis, and Malaria, May 2018, https://www.theglobalfund.org/media/7409/bm39 02-eligibility policy en.pdf?u $=636628658560000000$ 
Table 3. Projected Gavi Transitions 2015-2040, Ranked by Estimate Fiscal Impact ${ }^{32}$

\begin{tabular}{|c|c|c|c|c|c|c|c|c|c|c|c|c|c|c|c|c|c|c|c|c|c|c|c|}
\hline Country & ํㅠㅇ & & & & & 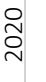 & & & & & & & & તุ & ֶి & & & ֻૃ & $\stackrel{\text { }}{\text { }}$ & & ㅇํ & 2017 Disbursements & $\begin{array}{c}\text { As \% of GGHE-D } \\
\text { (2015) }\end{array}$ \\
\hline Eritrea & $E$ & $E$ & $E$ & $E$ & $P$ & $P P$ & $P$ & $P$ & $P$ & $P$ & $P$ & & & A A & A A & A & G & G & G G & $G$ & G G G & $\$ 3,764,487$ & $19.0 \%$ \\
\hline Sao Tome and Principe & P & $P$ & $P$ & P & A & A A & A & A & G & G & G & & G & G C & G G & G & G & G & G G & $G$ & G G G & $\$ 1,515,216$ & $13.1 \%$ \\
\hline Benin & $E$ & $E$ & $E$ & $E$ & $\mathrm{E}$ & $E E$ & $P$ & $P$ & P & $P$ & $P$ & & $P$ & $P P$ & $P P$ & $P$ & $P$ & & $P P$ & $P$ & $A A A$ & $\$ 7,582,630$ & $11.4 \%$ \\
\hline Côte d'Ivoire & $P$ & $P$ & $P$ & $P$ & P & A A & A & A & A & G & G & & G & G C & G G & G & G & & G G & $G$ & G G G & $\$ 39,073,165$ & $9.9 \%$ \\
\hline Ethiopia & $E$ & $E$ & $E$ & $E$ & E & $P P$ & P & P & P & P & P & & P & P P & $P P$ & A & A & A & A A & G & $G G G$ & $\$ 63,776,700$ & $9.1 \%$ \\
\hline Bangladesh & $E$ & P & $P$ & $P$ & $\mathrm{P}$ & A A & A & A & A & G & G & & G & G C & G G & G & G & G & G G & $G$ & G G G & $\$ 67,075,861$ & $8.9 \%$ \\
\hline Timor-Leste & A & A & A & G & G & G G & G & G & G & G & G & G & G & G C & G G & G & G & G & G G & $G$ & G G G & $\$ 2,613,246$ & $8.4 \%$ \\
\hline Senegal & $E$ & $E$ & $E$ & P & $P$ & $P P$ & $P$ & P & P & P & P & & P & P P & $P A$ & A & A & A & A G & $G$ & G G G & $\$ 10,996,945$ & $6.4 \%$ \\
\hline Pakistan & P & $\mathrm{P}$ & $P$ & $P$ & $P$ & $P P$ & A & A & f & A & A & & ; & G C & $\mathrm{G} G$ & G & G & G & G G & $G$ & G G G & $\$ 115,138,076$ & $5.8 \%$ \\
\hline Cambodia & E & P & $P$ & $P$ & $P$ & $P P$ & A & A & A & A & A & & G & G G & $G G$ & G & G & G & G G & $G$ & G G G & $\$ 10,838,495$ & $4.5 \%$ \\
\hline Zimbabwe & $E$ & $E$ & $P$ & $P$ & $P$ & $P P$ & $P$ & $P$ & $P$ & P & $P$ & $P$ & $P$ & $P P$ & $P P$ & $P$ & $P$ & $P F$ & $P P$ & $P$ & $\mathrm{~A} A \mathrm{~A}$ & $\$ 15,127,625$ & $4.3 \%$ \\
\hline Tanzania & $E$ & $E$ & $P$ & $P$ & $P$ & $P P$ & $\mathrm{P}$ & P & P & P & P & & A & A A & A A & G & G & G & G G & $G$ & $G G G$ & $\$ 40,235,603$ & $4.1 \%$ \\
\hline Nigeria & P & $\mathrm{P}$ & A & A & A & A A & G & G & G & G & G & & G & G G & G G & G & G & G & G G & $G$ & $G G G$ & $\$ 109,071,924$ & $3.8 \%$ \\
\hline Cameroon & P & $\mathrm{P}$ & $P$ & $P$ & $P$ & $P P$ & $P$ & $P$ & P & P & $P$ & P & A & A A & A A & A & G & G & G G & $G$ & G G G & $\$ 7,922,614$ & $3.5 \%$ \\
\hline Myanmar & $E$ & P & $P$ & $P$ & $P$ & $P A$ & $A$ & A & A & A & G & $G$ & G & G G & G G & G & G & G & G G & $G$ & $G G G$ & $\$ 22,894,630$ & $3.4 \%$ \\
\hline Nepal & E & $E$ & $E$ & $E$ & $\mathrm{E}$ & E P & $P$ & P & P & P & P & $P$ & P & $P P$ & $P P$ & A & A & $f$ & A A & G & G G G & $\$ 7,170,534$ & $3.0 \%$ \\
\hline Zambia & $\mathrm{P}$ & $\mathrm{P}$ & $P$ & $P$ & $\mathrm{P}$ & $P P$ & $P$ & $P$ & A & A & A & & A & G G & G G & G & G & & G G & $G$ & $G G G$ & $\$ 12,417,325$ & $3.0 \%$ \\
\hline Lao P.D.R. & P & $\mathrm{P}$ & A & A & A & A A & G & G & c & G & G & & 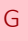 & G G & G G & G & G & G & G G & & G G G & $\$ 4,247,638$ & $3.0 \%$ \\
\hline Kenya & $E$ & $\mathrm{P}$ & $P$ & $P$ & A , & A A & A & A & & G & G & & G & G G & G G & G & G & G & G G & $G$ & G G G & $\$ 24,823,663$ & $2.3 \%$ \\
\hline Djibouti & P & $P$ & $P$ & $\mathrm{P}$ & A & A A & A & A & G & G & G & & G & G G & G G & G & G & C & G G & & G G G & $\$ 856,362$ & $2.1 \%$ \\
\hline Ghana & $E$ & P & $P$ & $P$ & P & A A & A & A & $F$ & G & G & & G & G G & $\mathrm{G} G$ & G & G & G & G G & G & G G G & $\$ 15,626,492$ & $2.0 \%$ \\
\hline Kyrgyz Republic & $\mathrm{P}$ & P & $P$ & $P$ & $P$ & $P P$ & $P$ & P & P & P & $\mathrm{P}$ & & P & $P P$ & $P A$ & A & A & A & A G & G & $G G G$ & $\$ 3,415,785$ & $1.4 \%$ \\
\hline Republic of Congo & A & A & A & G & G & G G & G & G & & G & G & & 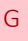 & G G & G G & G & 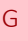 & G & G G & G & G G G & $\$ 1,699,912$ & $1.3 \%$ \\
\hline Sudan & $\mathrm{P}$ & P & $P$ & $P$ & A & A A & A & A & G & G & G & & 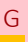 & G G & G G & G & G & G & G G & G & G G G & $\$ 21,575,749$ & $1.1 \%$ \\
\hline Lesotho & P & $\mathrm{P}$ & $\mathrm{P}$ & $P$ & $P$ & $P P$ & $P$ & $P$ & H & A & A & $F$ & A & G G & G G & G & G & G & G G & & G G G & $\$ 904,871$ & $0.8 \%$ \\
\hline Solomon Islands & $\mathrm{P}$ & $\mathrm{P}$ & A & A & A & A A & A & G & & $G$ & G & & 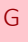 & G G & G G & G & G & 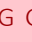 & G G & G & G G G & $\$ 423,846$ & $0.8 \%$ \\
\hline India & P & $P$ & $\mathrm{P}$ & A & A & A A & A & G & & G & G & & 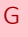 & G G & G G & G & G & G & G G & & G G G & $\$ 149,505,531$ & $0.7 \%$ \\
\hline Angola & A & A & A & G & $\mathrm{G}$ & G G & G & G & $C$ & G & G & & G & G G & G G & G & G & G & G G & & G G G & $\$ 10,088,927$ & $0.7 \%$ \\
\hline Papua New Guinea & $\mathrm{P}$ & 17 & A & A & A & A G & G & G & & G & G & & $G$ & G G & $G G$ & G & G & c & G G & & G G G & $\$ 3,399,742$ & $0.6 \%$ \\
\hline Indonesia & A & H & G & G & G & G G & G & G & & 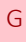 & 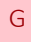 & & 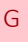 & G G & G G & G & 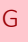 & 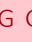 & G G & & $G G G$ & $\$ 35,290,409$ & $0.4 \%$ \\
\hline Armenia & A & A & A & G & G & G G & G & G & G & G & G & & G & G G & G G & G & G & G & G G & & G G G & $\$ 571,275$ & $0.3 \%$ \\
\hline Guyana & 4 & ta & G & G & G & G G & $G$ & G & G & G & G & & G & G G & G G & G & 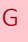 & ( & G G & & G G G & $\$ 178,500$ & $0.2 \%$ \\
\hline Bolivia & A & A & A & G & $\mathrm{G}$ & G G & G & G & & 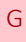 & 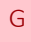 & & 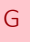 & G G & $G G$ & G & 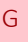 & 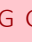 & G G & G & $G G G$ & $\$ 3,165,619$ & $0.2 \%$ \\
\hline Nicaragua & $\mathrm{P}$ & A & A & A & A & A G & G & G & G & G & G & & 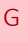 & G C & G G & G & G & G & G G & & G G G & $\$ 915,733$ & $0.2 \%$ \\
\hline Moldova & A & A & G & G & G & G G & G & G & & G & G & & G & G C & G G & G & G & C & G G & G & $G G G$ & $\$ 458,254$ & $0.2 \%$ \\
\hline Sri Lanka & 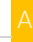 & 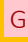 & G & G & G & G G & G & G & & 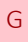 & 0 & & 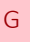 & G C & G G & G & 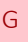 & 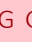 & G G & G & $G G G$ & $\$ 1,786,323$ & $0.1 \%$ \\
\hline Azerbaijan & 4 & A & A & G & G & G G & G & G & G & G & G & & G & G C & G G & G & G & G & G G & & G G G & $\$ 834,407$ & $0.1 \%$ \\
\hline Georgia & 4 & A & A & G & G & G G & G & G & G & G & G & & G & G C & G G & G & G & G & G G & & G G G & $\$ 425,270$ & $0.1 \%$ \\
\hline Bhutan & 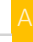 & G & G & G & $\mathrm{G}$ & G G & $G$ & G & 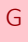 & 0 & G & $\checkmark$ & $\checkmark$ & G C & G G & G & 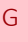 & G & G G & & G G G & $\$ 39,312$ & $0.1 \%$ \\
\hline Vietnam & -1 & A & A & A & A & G G & G & G & & G & G & & & G C & G G & G & G & & G G & G & G G G & $\$ 2,843,464$ & $0.1 \%$ \\
\hline Uzbekistan & A & A & A & A & A & G G & G & G & G & G & G & & G & G C & G G & G & $G$ & G & G G & G & G G G & $\$ 1,034,762$ & $0.0 \%$ \\
\hline Honduras & & U & G & G & G & G G & $G$ & C & 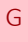 & 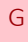 & 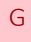 & & 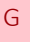 & G C & G G & G & 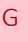 & 4 & G G & & G G G & $\$ 43,042$ & $0.0 \%$ \\
\hline Mongolia & 4 & G & G & G & G & G G & G & G & G & G & G & & G & G C & G G & G & G & G C & G G & G & G G G & $\$ 1,698$ & $0.0 \%$ \\
\hline Kiribati & A & & G & G & G & G G & G & G & G & G & G & & G & G C & $\mathrm{G} \mathrm{G}$ & G & G & G & G G & G & G G G & $\$ 0$ & $0.0 \%$ \\
\hline
\end{tabular}

Notes: Green "E”: eligible. Yellow "P”: "Preparatory Transition.” Orange “A”: “Accelerated Transition.” Red "G": graduated/Fully Self-Financing. ${ }^{32}$ Fiscal impact is calculated as 2017 Gavi disbursements divided by estimated general government health
expenditure for 2015 . 
Results indicate that the portfolio of Gavi-eligible countries will change dramatically by 2040. In total, 69 countries from the dataset ${ }^{33}$ were eligible for Gavi support at the beginning of the analysis period (2015). By 2018, 15 countries had fully transitioned from Gavi support; these countries had received $\$ 57.2$ million in 2017 disbursements, accounting for 5 percent of total Gavi expenditure. (As these countries were already in the accelerated transition phase, this amount represents a substantial decline from peak funding levels for these countries). By the end of 2025, another 16 countries are expected to transition from Gavi support; this cohort of countries received $\$ 464.9$ million in 2017 disbursements, accounting for 40 percent of Gavi's 2017 expenditure. By the end of the analysis period (2040), 11 additional countries are projected to become fully self-financing; these countries received $\$ 299.3$ million in 2017, or 25 percent of Gavi disbursements in 2017. Just 27 countriesaccounting for $\$ 376.5$ million in 2017 disbursements (32 percent of all disbursements) —will remain eligible for Gavi support in 2040 (Appendix 4). Assuming constant outlay per country, this means that total Gavi expenditure will drop 68 percent by 2040 compared to the 2017 baseline.

It is evident that Gavi will see a significant acceleration in the pace of transition over the near- to medium-term future. By 2025 or thereabouts, several of the largest recipients of Gavi funding — including India, Pakistan, Nigeria, and Bangladesh—will lose eligibility for its support. However, fiscal impact does not neatly correlate to the aggregate size of Gavi disbursements and varies widely. Among countries that had not yet entered accelerated transition by 2017 but are anticipated to fully transition by 2040, 2017 Gavi support as a percent of estimated government health expenditure ranged from a low of 0.7 percent (India) to a high of 19.0 percent (Eritrea), with a median of 3.4 percent and mean of 5.2 percent. Importantly, however, many of the countries with the highest projected fiscal impact will not face transition until the latter years of this analysis; in the interim, it is likely that their domestic expenditure on health will rise substantially, reducing their level of dependence on external funds.

\section{The Global Fund to Fight AIDS, Tuberculosis, and Malaria}

The Global Fund follows an explicit eligibility policy based primarily on two factors: GNI per capita (approximated here by GDP per capita) and disease burden. Eligibility is determined annually for each of the Global Fund's three disease areas (HIV, tuberculosis, and malaria); in any given year, a country may be eligible for one, two, or all three of the disease components. Global Fund financing is allocated over a fixed three-year cycle, e.g. 2014-2016, 2017-2019, 2020-2022, etc., and changes in eligibility caused by changing disease burden or GNI per capita growth are applied to the next funding cycle. For example, if a country hits HIC status in 2018 and therefore become ineligible for future funding, it will nonetheless continue to receive its allocation through 2019-but it will not be eligible for an allocation during the 2020-2022 cycle. Likewise, if a country with a moderate disease burden for HIV crosses the UMIC threshold in 2018, it will be eligible for one additional cycle of

\footnotetext{
33 As previously discussed, analysis excludes Cook Islands, Cuba, Egypt, Montserrat, Niue, North Korea, Pakistan, Somalia, St. Helena, Syria, and the West Bank/Gaza.
} 
transition funding from 2020-2022; it will thereafter become ineligible for financing during the 2023-2025 cycle.

I first project Global Fund transitions based on a baseline disease burden scenario-that is, assuming that no countries progress from "not high" to "high" disease burdens based on the Global Fund's criteria (Table 4). This is a somewhat pessimistic assumption, as it suggests the Global Fund does not achieve success in its core mission of containing-and eventually ending - the three diseases. For the purposes of the eligibility policy, however, this may be a realistic assumption. The disease categories are quite broad, and changes in disease burden only matter in determining eligibility at one threshold. In addition, HIV disease burden categories are based on HIV prevalence; since HIV is a life-long chronic disease, and part of the Global Fund's mandate is to keep HIV-positive individuals alive through ARV treatment, even a very successful HIV program is unlikely to cause a major reduction in national prevalence in the near term.

\section{Table 4. Definition of "High" Disease Burden for Determining Global Fund Eligibility ${ }^{34}$}

\begin{tabular}{l|l|l}
\multicolumn{1}{c}{ HIV / AIDS } & \multicolumn{1}{c}{ Tuberculosis } & \multicolumn{1}{c}{ Malaria $^{35}$} \\
$\begin{array}{l}\text { HIV national prevalence } \\
\text { greater than or equal to }(\geq) \\
1 \%\end{array}$ & $\begin{array}{l}\text { TB incidence rate per 100,000 } \\
\text { greater than or equal }(\geq) \text { to } 50\end{array}$ & $\begin{array}{l}\text { Mortality rate greater than or } \\
\text { equal to }(\geq) 0.12\end{array}$ \\
$\begin{array}{l}\text { OR } \\
\begin{array}{l}\text { Orevalence in a key population } \\
\text { greater than or equal to }(\geq)\end{array}\end{array}$ & $\begin{array}{l}\text { Proportion of new TB cases } \\
\text { who are drug resistant } \\
\text { (resistance to rifampicin) } \\
\text { greater than or equal }(\geq) \text { to } 5 \\
\text { percent. }\end{array}$ & $\begin{array}{l}\text { Contribution to global deaths } \\
\text { greater than or equal to }(\geq) 0.25 \%\end{array}$ \\
OR
\end{tabular}

Tables 5a, 5b, and 5c illustrate projected Global Fund transitions for HIV, TB, and malaria (respectively) through 2040 under this baseline scenario. Eligible country-year pairs are coded with a green "E"; transition funding is coded with a yellow "T"; and years after which a country has fully transitioned are coded with a red "G." By 2040, 20 countries are expected

${ }^{34}$ The Global Fund Sustainability, Transition and Co-financing Policy," The Global Fund, May 2018, https: / / www.theglobalfund.org/media $/ 7443 /$ core eligibility policy en.pdf?u $=636635807340000000$

${ }^{35}$ Malaria eligibility is based on 2000 data. 
to transition from Global Fund financing for HIV (out of 97 eligible countries ${ }^{36}$ in 2017); 18 countries are expected to transition from TB financing (out of 91 eligible countries in 2017); and 11 countries are expected to transition from malaria financing (out of 66 eligible countries in 2017). The set of transitioning countries accounts for $\$ 47$ million of 2017 financing for HIV (2.7 percent of all HIV financing); $\$ 28$ million of 2017 financing for TB (4.7 percent of all TB financing); and \$49 million of 2017 financing for malaria (4.4 percent of all malaria financing). Combined, they account for $\$ 124$ million in total annual financing_-or 3.6 percent of all Global Fund country allocations. Put differently, this implies that under the baseline disease burden scenario-and assuming constant allocations per eligible country - transition alone would result in just a 3.6 percent drop in total Global Fund outlays. (Of course, this finding only identifies the impact of ineligibility-it does not account for reductions or increases in future replenishments, or relative changes in country funding that may result from the Global Fund's allocation methodology, which is itself based in large part on GNI per capita and country disease burden.)

\footnotetext{
36 Including countries receiving transition funding. Excludes countries technically rated as eligible which did not receive an allocation for the 2017-2019 cycle, and countries otherwise excluded from this analysis.
} 
Table 5a. Projected Global Fund HIV Transitions 2015-2040, by 2017 Financing as \% of GGHE-D

\begin{tabular}{|c|c|c|c|c|c|c|c|c|}
\hline & $\stackrel{\sim}{\stackrel{n}{\curvearrowright}}$ & ্ָণ & 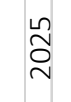 & 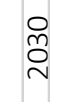 & 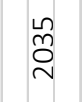 & ণ্ণ & Annual Total & $\begin{array}{c}\text { Annual Allocation as \% } \\
\text { of GGHE-D (2015) }\end{array}$ \\
\hline Guyana & \multicolumn{6}{|c|}{ E E E E EEEEEE E E E EGGGGGGGG } & $\$ 1,331,112$ & $1.8 \%$ \\
\hline Lao P.D.R. & \multicolumn{6}{|c|}{ E E E E EEEEEE E E E T T T GGGGGG } & $\$ 2,458,032$ & $1.7 \%$ \\
\hline Armenia & \multicolumn{6}{|c|}{ E E E E E T T T G G G G G G G G G G G G G G } & $\$ 1,760,927$ & $1.0 \%$ \\
\hline Botswana & \multicolumn{6}{|c|}{ E E E EEEEEEEE EE EGGGGGGGG } & $\$ 4,650,289$ & $1.0 \%$ \\
\hline Bangladesh & \multicolumn{6}{|c|}{ EEEEEEEEEEE EE EEEETTTGGG } & $\$ 6,098,482$ & $0.8 \%$ \\
\hline Bhutan & \multicolumn{6}{|c|}{ E E E E E E E T T T GGGGGGGGGGGGGGG } & $\$ 360,634$ & $0.7 \%$ \\
\hline Sudan & \multicolumn{6}{|c|}{ E E E E TTTGGGGGGGGGGGGGGGGG } & $\$ 6,279,907$ & $0.3 \%$ \\
\hline Dominican Republic & \multicolumn{6}{|c|}{ E E E EEEEEEEE GGGGGGGGGGGG } & $\$ 5,331,652$ & $0.3 \%$ \\
\hline Mauritius & \multicolumn{6}{|c|}{ E E E E E E E GGGGGGGGGGGGGGGGGG } & $\$ 829,306$ & $0.3 \%$ \\
\hline Sri Lanka & \multicolumn{6}{|c|}{$\mathrm{E} E \mathrm{~T} T \mathrm{~T}$ G G G G G G G G G G G G G G G G G G G } & $\$ 2,316,016$ & $0.2 \%$ \\
\hline Montenegro & \multicolumn{6}{|c|}{ EEEEEEEEEEEEEEEEEEEGG } & $\$ 232,058$ & $0.1 \%$ \\
\hline Albania & \multicolumn{6}{|c|}{ 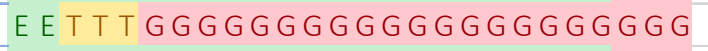 } & $\$ 379,378$ & $0.1 \%$ \\
\hline Thailand & \multicolumn{6}{|c|}{ EEEEEEEEEEEEEEEEEEEGG } & $\$ 8,189,717$ & $0.1 \%$ \\
\hline Peru & \multicolumn{6}{|c|}{ EEEEEEEEEEEEEEEEEEGGG } & $\$ 2,088,195$ & $0.0 \%$ \\
\hline Panama & \multicolumn{6}{|c|}{ E E E E E G G G G G G G G G G G G G G G G G } & $\$ 593,128$ & $0.0 \%$ \\
\hline Serbia & \multicolumn{6}{|c|}{ EEEEEEEEEEE E E E E EE E E GGG } & $\$ 457,646$ & $0.0 \%$ \\
\hline Malaysia & \multicolumn{6}{|c|}{ E E E E EE EGGGGGGGGGGGGGGGG } & $\$ 1,343,864$ & $0.0 \%$ \\
\hline Kazakhstan & \multicolumn{6}{|c|}{ E EEEEEEEEGGGGGGGGGGGGGG } & $\$ 904,741$ & $0.0 \%$ \\
\hline Costa Rica & \multicolumn{6}{|c|}{ E E E E G G G G G G G G G G G G G G G G G } & $\$ 706,699$ & $0.0 \%$ \\
\hline Algeria & \multicolumn{6}{|c|}{$\mathrm{E} E \mathrm{~T} T \mathrm{~T}$ G G G G G G G G G G G G G G G G G G } & $\$ 770,979$ & $0.0 \%$ \\
\hline
\end{tabular}

Notes: Green “E”: eligible. Yellow “T”: transition funding. Red “G”: graduated. 
Table 5b. Projected Global Fund TB Transitions 2015-2040, by 2017 Financing as \% of GGHE-D

\begin{tabular}{|c|c|c|c|c|c|c|c|c|}
\hline & $\stackrel{n}{\stackrel{n}{\sim}}$ & ָ̊ & $\stackrel{\sim}{\sim}$ & ஜे & $\stackrel{\sim}{\sim}$ & @ & $\begin{array}{l}\text { Annualized TB } \\
\text { Allocation }\end{array}$ & $\begin{array}{c}\text { Annual Allocation as \% } \\
\text { of GGHE-D (2015) }\end{array}$ \\
\hline Armenia & \multicolumn{6}{|c|}{ EE EE ETTTGGGGGGGGGGGGGGGGG } & $\$ 1,046,308$ & $0.6 \%$ \\
\hline Belize & \multicolumn{6}{|c|}{ E E T T T GGGGGGGGGGGGGGGGGGG } & $\$ 179,276$ & $0.2 \%$ \\
\hline Turkmenistan & \multicolumn{6}{|c|}{ EETTTEEEEEGGGGGGGGGGGGGG } & $\$ 1,318,888$ & $0.2 \%$ \\
\hline Nicaragua & \multicolumn{6}{|c|}{ EEEEEEEEEEEEEETTTGGGGGG } & $\$ 1,376,572$ & $0.2 \%$ \\
\hline Guyana & \multicolumn{6}{|c|}{ EEEEEEEEEEEEEEGGGGGGGGG } & $\$ 166,667$ & $0.2 \%$ \\
\hline Sudan & \multicolumn{6}{|c|}{ EEEEEEETTTGGGGGGGGGGGGGG } & $\$ 4,087,350$ & $0.2 \%$ \\
\hline Guatemala & \multicolumn{6}{|c|}{ EEEETTTTGGGGGGGGGGGGGGGG } & $\$ 1,949,828$ & $0.2 \%$ \\
\hline Botswana & \multicolumn{6}{|c|}{ EEEEEEEEEEEEEEGGGGGGGG } & $\$ 638,824$ & $0.1 \%$ \\
\hline El Salvador & \multicolumn{6}{|c|}{ EEEE $E T T T G G G G G G G G G G G G G G G$} & $\$ 1,414,247$ & $0.1 \%$ \\
\hline Dominican Republic & \multicolumn{6}{|c|}{ EETTTEEEEEEEEGGGGGGGGGG } & $\$ 1,497,947$ & $0.1 \%$ \\
\hline Paraguay & \multicolumn{6}{|c|}{ E E TT T GGGGGGGGGGGGGGGGGG } & $\$ 971,774$ & $0.1 \%$ \\
\hline Sri Lanka & \multicolumn{6}{|c|}{ EEEETTTGGGGGGGGGGGGGGGGG } & $\$ 1,008,024$ & $0.1 \%$ \\
\hline Kazakhstan & \multicolumn{6}{|c|}{ E EEEEEEEEGGGGGGGGGGGGGG } & $\$ 3,280,147$ & $0.1 \%$ \\
\hline Albania & \multicolumn{6}{|c|}{ 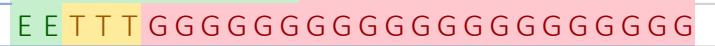 } & $\$ 166,667$ & $0.1 \%$ \\
\hline Peru & \multicolumn{6}{|c|}{ 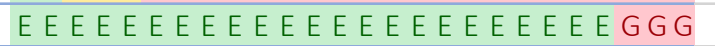 } & $\$ 2,399,764$ & $0.0 \%$ \\
\hline Thailand & \multicolumn{6}{|c|}{ EEEEEEEEEEEEEEEEEEEEGGG } & $\$ 4,365,503$ & $0.0 \%$ \\
\hline Romania & \multicolumn{6}{|c|}{ E E E EE E EGGGGGGGGGGGGGGGG } & $\$ 1,688,738$ & $0.0 \%$ \\
\hline Panama & \multicolumn{6}{|c|}{ E E T T T GGGGGGGGGGGGGGGGGG } & $\$ 302,169$ & $0.0 \%$ \\
\hline
\end{tabular}

Notes: Green "E”: eligible. Yellow “T”: transition funding. Red "G”: graduated.

Table 5c. Projected Global Fund Malaria Transitions 2015-2040, by 2017 Financing as $\%$ of GGHE-D

\begin{tabular}{|c|c|c|c|c|c|c|c|c|}
\hline & $\stackrel{n}{\stackrel{n}{\sim}}$ & ્ֻণి & $\stackrel{\sim}{\sim}$ & ণ্ণ & $\stackrel{\sim}{\tilde{N}}$ & ণ্ণ & Annual Total & $\begin{array}{c}\text { Annual Allocation as \% } \\
\text { of GGHE-D (2015) }\end{array}$ \\
\hline Sudan & \multicolumn{6}{|c|}{ EEEEEEEEEEEEEEEEEEEGGG } & $32,840,998$ & $1.7 \%$ \\
\hline Bhutan & \multicolumn{6}{|c|}{ E E E E E E ETTTGGGGGGGGGGGGG } & 477,490 & $0.9 \%$ \\
\hline Guyana & \multicolumn{6}{|c|}{ EEEEEEEEEEEEEEGGGGGGGG } & 537,340 & $0.7 \%$ \\
\hline Cabo Verde & \multicolumn{6}{|c|}{ EEEEEEEEETTTGGGGGGGGGGGG } & 371,292 & $0.7 \%$ \\
\hline Nicaragua & \multicolumn{6}{|c|}{ EEEEEEEEEEEEEEEETTTGGGGGG } & $2,145,179$ & $0.4 \%$ \\
\hline Guatemala & \multicolumn{6}{|c|}{ EEEETTTGGGGGGGGGGGGGGGG } & $2,120,853$ & $0.2 \%$ \\
\hline Botswana & \multicolumn{6}{|c|}{ 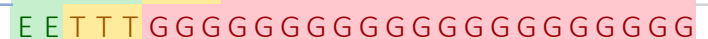 } & 429,167 & $0.1 \%$ \\
\hline Bolivia & \multicolumn{6}{|c|}{ EEEETTTGGGGGGGGGGGGGGGG } & $1,269,287$ & $0.1 \%$ \\
\hline Philippines & \multicolumn{6}{|c|}{ EEEE ETTTGGGGGGGGGGGGGGGG } & $3,554,272$ & $0.1 \%$ \\
\hline Sri Lanka & \multicolumn{6}{|c|}{ E E T T T GGGGGGGGGGGGGGGGGGGG } & 833,333 & $0.1 \%$ \\
\hline Thailand & \multicolumn{6}{|c|}{ 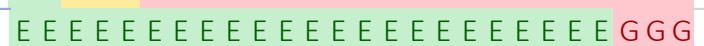 } & $4,434,749$ & $0.0 \%$ \\
\hline
\end{tabular}

Notes: Green "E”: eligible. Yellow “T”': transition funding. Red "G”: graduated. 
Examining the cohort of transitioning countries, a few characteristics stand out. First, most transitioning countries appear to have a relatively low level of Global Fund-dependence, measured here by total Global Fund financing in 2017 as a percentage of estimated government expenditure on health. With just a few exceptions (Sudan malaria, Guyana HIV, and Lao HIV), Global Fund financing for any given disease component (among the cohort of transitioning country-component pairs) accounts for no more than one percent of GGHE-D. Second, the absolute levels of funding are quite low. Finally, the absolute number of country-disease component pairs expected to transition by 2040 (49) is relatively lowaccounting for 19 percent of all eligible country-disease-component pairs in 2017.

Taking a broader view across the entirety of the Global Fund portfolio, Appendix 5a shows projected transitions among the top 20 recipients of Global Fund financing (by countrydisease component pair). Among these largest recipients of Global Fund financing, no country-component pair is projected to transition by 2040. The same holds true when examining the 20 most aid-dependent recipients (Appendix 5b); no country in this grouping is projected to transition during the period of analysis.

To test the robustness of these results, I also model a "universal progress scenario" for HIV and tuberculosis (Appendix 6). (The malaria component is based on data from 2000, so reductions in the malaria disease burden would not affect eligibility for malaria funding under the current policy). Under this scenario, the Global Fund sees more success in achieving its core mission, and by 2025 all countries have moved up one category in the more precise disease burden ratings it used under its previous eligibility system (see Appendix 2), e.g. from extreme to severe, severe to high, high to moderate, or moderate to low. Countries that began the period with a low disease burden continue to see a low disease burden.

The assumption of universal progress expands the universe of transitioning countries by 2040. For HIV, 45 countries would transition by 2040, compared to 20 under the baseline scenario; and for TB, 27 countries would transition, compared to 18 under baseline. Under this scenario, India, Myanmar, and Indonesia would represent large additional transitions from HIV; Nigeria would also transition from TB funding in 2035. These changes drive an expansion in the proportion of the 2017 portfolio impacted by transition compared to baseline, from 2.7 percent to 15.5 percent for HIV, and 4.7 percent to 12.5 percent for TB. In total, even under this optimistic scenario, transitions through 2040 would affect just 11 percent of Global Fund 2017 financing. Once again, no transitions would be projected to take place among the most aid-dependent countries.

\section{International Development Association}

IDA transition is somewhat more difficult to predict than transition for Gavi or the Global Fund. Generally, a country becomes eligible for IDA transition once its GNI per capita crosses the set threshold, currently $\$ 1,165$ in $2018 .{ }^{37}$ In addition, other countries that lack

\footnotetext{
37 “Borrowing Countries," International Development Association, World Bank, 2018, http://ida.worldbank.org/about/borrowing-countries.
} 
creditworthiness to borrow from the International Bank for Reconstruction and Development (IBRD) may also be granted access to IDA financing; this particularly applies to small island economies, which are often eligible for access to IDA financing at much higher levels of GNI per capita. More generally, there is often a significant lag between the point at which a country crosses the operational threshold and the point at which it formally graduates from IDA financing; previous analyses of historical transitions suggest a lag of six years, on average. ${ }^{38}$ Nonetheless, the length of the lag can vary substantially. For example, Bolivia received its final IDA credit in 2017,39 but had a GNI per capita above the current IDA threshold as early as 2007-a decade prior to graduation. Therefore, analysis can only identify those countries which are risk of transition — not those which will necessarily graduate in any given year.

Table 6 illustrates projected IDA transitions in the 2015-2040 period, assuming the 2018 threshold continues to apply throughout the entirety of the period. Countries that are under the threshold are denoted by a green "U"; countries that are eligible by virtue of their small island economy status are denoted by a green "I"; and countries that had already graduated by 2018 or are anticipated to graduate from small island economy status due to achieving HIC status, are denoted by a red "G." The remainder of countries are over the threshold, do not benefit from small island economy status, and are thus at risk of losing IDA eligibilitybut may not lose eligibility immediately. For the years we can directly observe (2015-2018), countries that are over the threshold but still listed as eligible for IDA financing are denoted by a green "O." In future years (2019-2040), countries that are over the threshold are coded with a yellow "O," indicating uncertainty about their eligibility status.

In total, 75 countries ${ }^{40}$ were eligible in 2015; of those, three countries graduated in 2017, another 27 countries were over the threshold but still eligible for financing in 2018, and 46 countries remained below the threshold or subject to small-island eligibility rules. By 2025, an additional 8 countries are projected to cross the threshold and two small island economies will likely lose eligibility due to HIC status, leaving 38 countries remaining. By 2040, another 13 countries will have crossed the threshold or lost small island eligibility, leaving a pool of just 25 countries below the threshold, or eligible due to their small island economy status (Table 7).

\footnotetext{
38 Scott Morris and Madeline Gleave, “The World Bank at 75," CGD Policy Paper 058, Washington: Center for Global Development, March 2015, https://www.cgdev.org/sites/default/files/world-bank-75-revised-3-26$150 . \mathrm{pdf}$

39 “IDA Graduates," International Development Association, World Bank, July 2017, http://ida.worldbank.org/about/ida-graduates.

${ }^{40}$ From our sample; this excludes Kosovo, Syria, and Somalia.
} 
Table 6. Projected IDA Transitions 2015-2040

\begin{tabular}{|c|c|c|c|c|c|c|c|c|c|c|c|c|c|c|c|c|c|c|c|c|c|c|c|}
\hline Country & 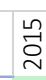 & & & & & §ి & & & & $\stackrel{\sim}{\stackrel{N}{\sim}}$ & & & & & ְે & & & & 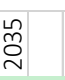 & & & & ষ্ণ \\
\hline Afghanistan & U & U & U & U & U & $U U$ & J U & U & U & U & U & U & U & U & $U U$ & $U$ & U & $U U$ & $U U$ & U & U & 0 & 0 \\
\hline Bangladesh & O & O & 0 & 0 & O & 00 & 0 & 0 & 0 & 0 & $\mathrm{O}$ & 0 & O & $\mathrm{OC}$ & 00 & 0 & 0 & 00 & 00 & 0 & 0 & 0 & 0 \\
\hline Benin & U & $U$ & $U$ & $U$ & U & $U U$ & J U & U & U & $U$ & $\mathrm{O}$ & 0 & 0 & OC & 00 & 0 & 0 & 00 & 00 & 0 & 0 & 0 & 0 \\
\hline Bhutan & 0 & 0 & $\mathrm{O}$ & 0 & O & 00 & 0 & O & 0 & 0 & 0 & 0 & 0 & OC & 00 & 0 & 0 & 00 & 00 & 0 & 0 & 0 & 0 \\
\hline Bolivia & 0 & O & O & G & G & G G & $G$ & G & G & G & G & G & G & G & G G & $G$ & G & G G & G G & G & G & G & G \\
\hline Burkina Faso & U & U & $\mathrm{U}$ & U & U & $U U$ & $J U$ & U & U & $U$ & $U$ & $U$ & $U$ & U & $U U$ & $U$ & 0 & 00 & 00 & 0 & 0 & 0 & 0 \\
\hline Cambodia & U & $\mathrm{O}$ & O & 0 & O & 00 & 0 & 0 & 0 & 0 & 0 & 0 & 0 & $\mathrm{OC}$ & 00 & 0 & 0 & 00 & 00 & 0 & 0 & 0 & 0 \\
\hline Cameroon & $\mathrm{O}$ & 0 & $\mathrm{O}$ & $\mathrm{O}$ & $\mathrm{O}$ & 00 & 0 & 0 & 0 & $\mathrm{O}$ & $\mathrm{O}$ & 0 & 0 & $\mathrm{OC}$ & 00 & 0 & 0 & 00 & 00 & 0 & 0 & 0 & O \\
\hline Central African Republic & U & $U$ & $U$ & U & U & $U U$ & J & $u$ & $u$ & $U$ & $U$ & $U$ & $U$ & U & $U U$ & J & $U$ & $U \cup$ & U $\underline{0}$ & 0 & 0 & 0 & O \\
\hline Côte d'Ivoire & $\mathrm{O}$ & $\mathrm{O}$ & $\mathrm{O}$ & $\mathrm{O}$ & o & 00 & 0 & $\mathrm{O}$ & 0 & $\mathrm{O}$ & $\mathrm{O}$ & $\mathrm{O}$ & $\mathrm{O}$ & o & 00 & 0 & 0 & 00 & 00 & 0 & 0 & 0 & $\mathrm{O}$ \\
\hline Djibouti & 0 & $\mathrm{O}$ & O & 0 & O & 00 & 0 & 0 & 0 & 0 & 0 & 0 & 0 & O & 00 & 0 & 0 & 00 & 00 & 0 & 0 & $\mathrm{O}$ & 0 \\
\hline Dominica & 1 & 1 & 1 & 1 & 11 & 11 & 1 & 1 & 1 & 1 & 1 & 1 & 1 & 11 & 11 & 1 & 1 & G G & G G & G & G & G & G \\
\hline Eritrea & U & $U$ & U & U & U & 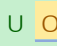 & 0 & 0 & 0 & 0 & 0 & 0 & 0 & O & 00 & 0 & 0 & 00 & 00 & 0 & 0 & 0 & 0 \\
\hline Ethiopia & U & $U$ & $U$ & $U$ & U & $U \bar{U}$ & $\mathrm{JU}$ & 0 & 0 & 0 & 0 & 0 & 0 & O & 00 & 0 & 0 & 00 & 00 & 0 & 0 & 0 & 0 \\
\hline Ghana & 0 & $\mathrm{O}$ & $\mathrm{O}$ & 0 & O & 00 & 0 & 0 & 0 & 0 & 0 & 0 & 0 & O & 00 & 0 & 0 & 00 & 00 & 0 & 0 & 0 & 0 \\
\hline Grenada & 1 & 1 & I & I & 11 & 11 & G & G & G & G & G & G & G & $\mathrm{G}$ & $\mathrm{G} G$ & $G$ & G & G G & G G & G & G & G & $\mathrm{G}$ \\
\hline Guinea-Bissau & U & $U$ & $U$ & $U$ & U & $\cup U$ & $U$ & U & U & $U$ & $U$ & U & $U$ & U & $\cup \cup$ & $U$ & U & 00 & 00 & 0 & 0 & 0 & 0 \\
\hline Guyana & $\mathrm{O}$ & $\mathrm{O}$ & $\mathrm{O}$ & $\mathrm{O}$ & O & 00 & 0 & O & O & 0 & $\mathrm{O}$ & $\mathrm{O}$ & $\mathrm{O}$ & O & 00 & 0 & $\mathrm{O}$ & 00 & 00 & $\mathrm{O}$ & 0 & $\mathrm{O}$ & $\mathrm{O}$ \\
\hline Honduras & 0 & O & $\mathrm{O}$ & $\mathrm{O}$ & O & 00 & 0 & O & 0 & 0 & 0 & $\mathrm{O}$ & $\mathrm{O}$ & O & 00 & 0 & 0 & 00 & 00 & 0 & 0 & 0 & $\mathrm{O}$ \\
\hline Kenya & 0 & $\mathrm{O}$ & $\mathrm{O}$ & $\mathrm{O}$ & O & 00 & 0 & 0 & $\mathrm{O}$ & $\mathrm{O}$ & $\mathrm{O}$ & $\mathrm{O}$ & $\mathrm{O}$ & O & 00 & 0 & 0 & 00 & 00 & $\mathrm{O}$ & 0 & $\mathrm{O}$ & $\mathrm{O}$ \\
\hline Kyrgyz Republic & U & $U$ & U & 0 & O & 00 & 0 & 0 & 0 & 0 & 0 & 0 & 0 & $\mathrm{O}$ & 00 & 0 & 0 & 00 & 00 & 0 & 0 & 0 & 0 \\
\hline Lao P.D.R. & O & 0 & $\mathrm{O}$ & 0 & O & 00 & 0 & 0 & 0 & 0 & 0 & 0 & 0 & o & 00 & 0 & 0 & 00 & 00 & 0 & 0 & 0 & 0 \\
\hline Lesotho & U & $\mathrm{O}$ & O & 0 & O & 00 & 0 & 0 & 0 & 0 & 0 & 0 & 0 & O & 00 & 0 & 0 & 00 & 00 & 0 & 0 & 0 & 0 \\
\hline Maldives & I & 1 & I & I & 11 & 11 & G & G & G & G & G & G & G & G & G G & $G$ & G & G G & G G & G & G & G & G \\
\hline Mali & U & $U$ & $U$ & U & U & $U U$ & $U$ & U & U & $U$ & U & U & U & U & $U \cup$ & $U$ & $U$ & $U U$ & U O & 0 & 0 & 0 & 0 \\
\hline Mauritania & O & 0 & $\mathrm{O}$ & O & O & 00 & 0 & 0 & 0 & $\mathrm{O}$ & 0 & 0 & 0 & O & 00 & 0 & 0 & 00 & 00 & 0 & 0 & 0 & 0 \\
\hline Moldova & 0 & 0 & 0 & 0 & O & 00 & 0 & 0 & 0 & 0 & 0 & 0 & 0 & $\mathrm{O}$ & 00 & 0 & 0 & 00 & 00 & 0 & 0 & 0 & 0 \\
\hline Mongolia & 0 & 0 & $\mathrm{O}$ & O & O & 00 & 0 & O & O & 0 & 0 & 0 & 0 & O & 00 & 0 & 0 & 00 & 00 & 0 & 0 & O & 0 \\
\hline Myanmar & U & $\mathrm{O}$ & $\mathrm{O}$ & 0 & O & 00 & 0 & O & O & 0 & 0 & $\mathrm{O}$ & 0 & O & 00 & 0 & 0 & 00 & 00 & 0 & 0 & $\mathrm{O}$ & $\mathrm{O}$ \\
\hline Nepal & U & $u$ & U & U & U & $U U$ & J U & $\mathrm{O}$ & O & 0 & 0 & 0 & 0 & O & 00 & 0 & $\mathrm{O}$ & 00 & 00 & 0 & 0 & $\mathrm{O}$ & $\mathrm{O}$ \\
\hline Nicaragua & O & O & $\mathrm{O}$ & O & O & 00 & 0 & 0 & 0 & 0 & 0 & 0 & 0 & 0 & 00 & 0 & 0 & 00 & 00 & 0 & 0 & 0 & 0 \\
\hline Nigeria & 0 & 0 & $\mathrm{O}$ & 0 & $\mathrm{O}$ & 00 & 0 & 0 & 0 & 0 & 0 & 0 & 0 & O & 00 & 0 & 0 & 00 & 00 & 0 & 0 & 0 & 0 \\
\hline Papua New Guinea & 0 & 0 & 0 & 0 & $\mathrm{O}$ & 00 & 0 & 0 & 0 & 0 & 0 & 0 & 0 & $\mathrm{O}$ & 00 & 0 & 0 & 00 & 00 & 0 & 0 & 0 & 0 \\
\hline Pakistan & 0 & $\mathrm{O}$ & $\mathrm{O}$ & 0 & 0 & 00 & 0 & 0 & 0 & 0 & 0 & 0 & 0 & 0 & 00 & 0 & 0 & 00 & 00 & 0 & 0 & 0 & 0 \\
\hline Republic of Congo & 0 & $\mathrm{O}$ & $\mathrm{O}$ & $\mathrm{O}$ & $\mathrm{O}$ & 00 & 0 & 0 & 0 & $\mathrm{O}$ & 0 & 0 & 0 & O & 00 & 0 & 0 & 00 & 00 & 0 & 0 & 0 & 0 \\
\hline Rwanda & U & $U$ & $\mathrm{U}$ & U & $U$ & $U U$ & J & U & U & $U$ & $U$ & U & U & U & 00 & 0 & O & 00 & 00 & 0 & 0 & 0 & 0 \\
\hline Senegal & U & $u$ & $u$ & U & U & U O & 0 & O & O & O & $\mathrm{O}$ & 0 & $\mathrm{O}$ & $\mathrm{O}^{-}$ & 00 & 0 & 0 & 00 & 00 & 0 & 0 & $\mathrm{O}$ & 0 \\
\hline Sierra Leone & U & U & U & U & U & $u \bar{U}$ & $\mathrm{~J}$ & U & u & U & U & U & U & U & 00 & 0 & 0 & 00 & 00 & 0 & 0 & 0 & 0 \\
\hline Sri Lanka & O & $\mathrm{O}$ & $\mathrm{O}$ & G & $\mathrm{G}$ & $\mathrm{G} \mathrm{G}$ & $\mathrm{G}$ & G & G & G & G & G & G & G & G G & $G$ & G & $\mathrm{G} \mathrm{G}$ & $\mathrm{G} G$ & G & G & G & G \\
\hline St. Vincent \& the Grenadines & I & 1 & I & 1 & 1 & 11 & 1 & I & 1 & 1 & 1 & 1 & I & 1 & I I & G & G & G G & G G & G & G & G & G \\
\hline Sudan & $\mathrm{O}$ & $\mathrm{O}$ & O & 0 & O & 00 & 0 & 0 & $\mathrm{O}$ & $\mathrm{O}$ & $\mathrm{O}$ & $\mathrm{O}$ & 0 & 0 & 00 & 0 & $\mathrm{O}$ & 00 & 00 & $\mathrm{O}$ & 0 & $\mathrm{O}$ & 0 \\
\hline Tajikistan & U & $U$ & $u$ & $u$ & $u$ & $U U$ & $J$ & $u$ & $u$ & $U$ & U & U & 0 & 0 & 00 & 0 & 0 & 00 & 00 & 0 & 0 & $\mathrm{O}$ & 0 \\
\hline Tanzania & U & U & U & U & O & 00 & 0 & O & 0 & 0 & O & 0 & 0 & 0 & 00 & 0 & 0 & 00 & 00 & 0 & 0 & 0 & 0 \\
\hline Timor-Leste & O & O & O & O & 0 & 00 & 0 & O & O & 0 & $\mathrm{O}$ & 0 & 0 & 0 & 00 & 0 & 0 & 00 & 00 & 0 & 0 & 0 & 0 \\
\hline Togo & U & $U$ & U & U & $U$ & $U U$ & $\mathrm{~J}$ & U & U & $U$ & U & U & U & U & $U U$ & $U$ & U & $U U$ & $U U$ & U & U & $U$ & 0 \\
\hline Uganda & U & U & U & U & U & $U \cup$ & J & u & u & $U$ & U & U & U & $u$ & $U U$ & J & U & $\cup U$ & U 0 & 0 & 0 & $\mathrm{O}$ & 0 \\
\hline Uzbekistan & O & $\mathrm{O}$ & $\mathrm{O}$ & $\mathrm{O}$ & O & 00 & 0 & O & $\mathrm{O}$ & $\mathrm{O}$ & $\mathrm{O}$ & $\mathrm{O}$ & $\mathrm{O}$ & 0 & 00 & 0 & $\mathrm{O}$ & 00 & 0 & 0 & 0 & $\mathrm{O}$ & $\mathrm{O}$ \\
\hline Vietnam & 0 & 0 & $\mathrm{O}$ & G & $\mathrm{G}$ & $\mathrm{G} \mathrm{G}$ & $G$ & G & G & G & G & G & G & G & G G & $G$ & G & $\mathrm{G} \mathrm{G}$ & $\mathrm{G} G$ & G & G & G & G \\
\hline Zambia & O & 0 & O & 0 & O & 00 & 0 & O & O & 0 & 0 & 0 & 0 & 0 & 00 & 0 & 0 & 00 & 00 & 0 & 0 & 0 & 0 \\
\hline Zimbabwe & U & $U$ & $U$ & U & & $U U$ & $\mathrm{~J}$ & $\mathrm{O}$ & 0 & 0 & 0 & & & & & & & 00 & 00 & 0 & & 0 & 0 \\
\hline
\end{tabular}

Notes: Green "U”: eligible, under threshold. Green "I": eligible, small island economy. Green "O”: eligible, over threshold. Yellow "O”: over threshold, unknown eligibility. Red "G”: graduated. 
Table 7. Remaining IDA-Eligible Countries, 2040

\begin{tabular}{|l|l|l|}
\hline Burundi & Madagascar & South Sudan \\
\hline Cape Verde* & Malawi & St. Lucia \\
\hline Chad & Marshall Islands* & The Gambia \\
\hline Comoros* & Micronesia* & Tonga \\
\hline DRC & Mozambique & Tuvalu* \\
\hline Guinea & Niger & Vanuatu* \\
\hline Haiti & Samo* & Yemen \\
\hline Kiribati* & Sao Tome* & \\
\hline Liberia & Solomon Islands* & \\
\hline
\end{tabular}

*Eligible under small island rule

\section{Global Polio Eradication Initiative}

The GPEI has historically spent about $\$ 1$ billion annually to support global polio eradication efforts, with funding and effort highly concentrated in a set of 16 priority countries that are either polio-endemic (Afghanistan, Pakistan, and Nigeria) or have recently eliminated polio but require support to prevent reintroduction. ${ }^{41}$ If recent setbacks can be overcome, the GPEI expects to continue winding down field operations, potentially with dramatic reductions in funding even before polio is formally eradicated. Though GPEI support is typically off-budget, its financing directly pays for 145 laboratories and more than 30,000 public health workers around the world, of whom 25-50 percent also support non-polio functions such as routine immunization, general disease surveillance, and supply chain/logistics strengthening.41 In a subset of priority countries, the fiscal and programmatic impacts of rapid transition would be substantial.

The entire set of GPEI priority countries, alongside GPEI financing for 2017 and the fiscal impact of GPEI expenditure relative to government expenditure on health, is presented in Table 8. GPEI support amounts to an estimated 85 percent of total government expenditure in Afghanistan, 34 percent in South Sudan, and above 10 percent in Chad, the Democratic Republic of the Congo, and Pakistan. (A relatively small portion of GPEI funding is channeled through Gavi to purchase inactivated polio vaccine and may thus be doublecounted with Gavi funding as reported above; however, the fiscal implications are relatively minor and do not change the overall findings of this analysis). In general, the fiscal impact of GPEI transitions is substantially higher than anticipated fiscal impact from Global Fund transitions; with the exceptions of Afghanistan and South Sudan, the fiscal impacts would be roughly comparable to near-term Gavi transitions (by 2025). Nonetheless, the relatively fast drawdown of funding that would follow eradication distinguish GPEI transition from Gavi's long-term, gradual process.

41 The End of the Beginning, Global Polio Eradication Initiative, July 2017, http://polioeradication.org/wpcontent/uploads/2017/07/TIMB Report-no1_Jul2017 EN.pdf 
Table 8. Fiscal Vulnerability from GPEI Transition ${ }^{42}$

Country

GPEI Disbursements (2017)

As \% of GGHE-D (2015)

Afghanistan

$\$ 87,124,000$

$85.1 \%$

South Sudan

$\$ 16,291,000$

$33.8 \%$

Chad

$\$ 18,294,000$

$15.6 \%$

Democratic Republic of the Congo

$\$ 31,603,000$

$11.8 \%$

Pakistan

$\$ 218,824,000$

$11.0 \%$

Nigeria

$\$ 210,598,000$

$7.4 \%$

Cameroon

$\$ 9,495,000$

$4.2 \%$

Ethiopia

$\$ 14,025,000$

$2.0 \%$

Nepal

$\$ 2,028,000$

$0.8 \%$

Angola

$\$ 7,155,000$

$0.5 \%$

Sudan

$\$ 7,955,000$

$0.4 \%$

Myanmar

$\$ 2,266,000$

$0.3 \%$

Bangladesh

$\$ 2,038,000$

$0.3 \%$

India

$\$ 37,767,000$

$0.2 \%$

Indonesia

$\$ 907,000$

$0.0 \%$

\section{The President's Emergency Plan for AIDS Relief (PEPFAR)}

PEPFAR is among the largest individual global health financiers, with bilateral disbursements of $\$ 3.33$ billion in 2016 (the last available year for disbursements) across 31 countries with country operational plans, plus an additional $\$ 50.3$ million spread across four regional programs. Importantly, PEPFAR does not have a formal eligibility or transition policy; priority countries have been chosen historically based on disease burden, the level of financial need, US relationships, and other subjective factors, and updated based on the chosen strategic direction under successive Global AIDS Coordinators (currently Ambassador Deborah L. Birx), with input from the US Congress. There is no explicit policy that can be used to anticipate the duration of PEPFAR support.

Nonetheless, it is important to incorporate PEPFAR into any discussion of global health transition for several reasons. First, its substantial resources are concentrated in a relatively small group of countries - meaning that the fiscal impact of PEPFAR withdrawal, or even a relatively minor percentage drop in financing, may be large. Second, PEPFAR's strategy for 2017-2020 designates a subset of 13 countries where PEPFAR intends to "accelerate" progress toward epidemic control. ${ }^{43}$ Given that PEPFAR's overall budget for bilateral programs has been roughly flat since $2009,{ }^{44}$ this may in turn imply a funding decreases in the remainder of countries that have historically received PEPFAR support. Even a relatively

\footnotetext{
42 Excludes Somalia.

43 “Strategy for Accelerating HIV/AIDS Epidemic Control (2017-2020)," PEPFAR, 2017, https://www.pepfar.gov/documents/organization/274400.pdf.

44 "PEFAR Funding," PEPFAR, https://www.pepfar.gov/documents/organization/252516.pdf.
} 
small reallocation of funding from non-acceleration countries to acceleration countries could have a dramatic fiscal impact. Third, PEPFAR support relies entirely on annual appropriations from the United States Congress. In recent years, congressional disfunction has affected the predictability and timeliness of the appropriations process, while pressure on the foreign aid budget has grown. The Trump administration has repeatedly signaled its desire to slash the foreign aid budget, and to curtail aid to those countries perceived as hostile to US foreign policy priorities. ${ }^{45}$ Under these circumstances, continuation of current PEPFAR funding levels, even in the short-term, cannot be taken for granted.

For the purposes of this analysis, I distinguish between the PEPFAR acceleration and nonacceleration countries as a highly imperfect proxy for the likelihood of funding cuts. Importantly, acceleration countries have not yet received explicit promises of increased funding. However, the administration's budget request for FY2018 is described as "focusing funds" on the 13 acceleration countries. Drawing from the same document and the FY2019 budget request, an analysis of country-level differences between the FY2018 and FY2019 PEPFAR budget requests and 2017 estimated actual funding suggests, in general, the intent to make significant reallocations of funding away from non-acceleration countries toward acceleration countries, at least in the event of overall budget cuts (see Table 9). Apart from South Africa, the requests for non-acceleration countries would imply potential funding cuts of 21-68 percent, totaling up to $\$ 141$ million in absolute terms (Nigeria). While these requests do not represent final allocations - and Congress is likely to reverse some or all suggested funding cuts or reallocations - the data suggests that acceleration versus non-nonacceleration is a meaningful if imprecise proxy for the likelihood and directionality of changes to future financial flows.

45 Carol Morello, 'Foreign aid cuts proposed, but 'friends' might be protected," Washington Post, February 18, 2018. 
Table 9. Change in PEPFAR Allocations, FY2017-2019, Based on FY2018-2019 Budget Requests

\begin{tabular}{|c|c|c|c|c|c|}
\hline & $\begin{array}{l}2017 \text { Estimated } \\
\text { PEPFAR } \\
\text { Allocations }\end{array}$ & $\begin{array}{c}2018 \text { PEPFAR } \\
\text { Budget } \\
\text { Request }\end{array}$ & $\begin{array}{l}2019 \text { PEPFAR } \\
\text { Budget Request }\end{array}$ & $\begin{array}{c}\% \text { Change } \\
\text { in } \\
\text { Funding } \\
2017-2019\end{array}$ & $\begin{array}{l}\text { Absolute Change } \\
\text { in Funding, 2017- } \\
2019\end{array}$ \\
\hline Botswana & $\$ 36,061,000$ & $\$ 60,000,000$ & $\$ 65,000,000$ & $80 \%$ & $\$ 28,939,000$ \\
\hline Malawi & $\$ 73,200,000$ & $\$ 120,000,000$ & $\$ 114,830,000$ & $57 \%$ & $\$ 41,630,000$ \\
\hline Uganda & $\$ 246,425,000$ & $\$ 370,000,000$ & $\$ 364,600,000$ & $48 \%$ & $\$ 118,175,000$ \\
\hline Rwanda & $\$ 53,010,000$ & $\$ 70,000,000$ & $\$ 70,000,000$ & $32 \%$ & $\$ 16,990,000$ \\
\hline Zambia & $\$ 298,932,000$ & $\$ 390,000,000$ & $\$ 384,600,000$ & $29 \%$ & $\$ 85,668,000$ \\
\hline Tanzania & $\$ 380,692,000$ & $\$ 470,000,000$ & $\$ 464,500,000$ & $22 \%$ & $\$ 83,808,000$ \\
\hline Cote d'Ivoire & $\$ 113,012,000$ & $\$ 140,000,000$ & $\$ 134,830,000$ & $19 \%$ & $\$ 21,818,000$ \\
\hline Haiti & $\$ 84,913,000$ & $\$ 85,000,000$ & $\$ 100,000,000$ & $18 \%$ & $\$ 15,087,000$ \\
\hline Lesotho & $\$ 61,708,000$ & $\$ 70,000,000$ & $\$ 70,000,000$ & $13 \%$ & $\$ 8,292,000$ \\
\hline South Africa & $\$ 450,132,000$ & $\$ 300,000,000$ & $\$ 500,000,000$ & $11 \%$ & $\$ 49,868,000$ \\
\hline Swaziland & $\$ 58,555,000$ & $\$ 60,000,000$ & $\$ 60,000,000$ & $2 \%$ & $\$ 1,445,000$ \\
\hline Namibia & $\$ 65,064,000$ & $\$ 65,000,000$ & $\$ 65,000,000$ & $0 \%$ & $-\$ 64,000$ \\
\hline Kenya & $\$ 496,210,000$ & $\$ 500,000,000$ & $\$ 489,494,000$ & $-1 \%$ & $-\$ 6,716,000$ \\
\hline Zimbabwe & $\$ 125,723,000$ & $\$ 125,000,000$ & $\$ 119,931,000$ & $-5 \%$ & $-\$ 5,792,000$ \\
\hline Vietnam & $\$ 28,914,000$ & $\$ 35,000,000$ & $\$ 22,831,000$ & $-21 \%$ & $-\$ 6,083,000$ \\
\hline Cameroon & $\$ 39,065,000$ & $\$ 30,000,000$ & $\$ 26,468,000$ & $-32 \%$ & $-\$ 12,597,000$ \\
\hline Dominican Republic & $\$ 7,463,000$ & $\$ 10,000,000$ & $\$ 4,545,000$ & $-39 \%$ & $-\$ 2,918,000$ \\
\hline Nigeria & $\$ 249,782,000$ & $\$ 250,000,000$ & $\$ 143,512,000$ & $-43 \%$ & $-\$ 106,270,000$ \\
\hline Mozambique & $\$ 327,330,000$ & $\$ 225,000,000$ & $\$ 186,585,000$ & $-43 \%$ & $-\$ 140,745,000$ \\
\hline South Sudan & $\$ 12,827,000$ & $\$ 20,000,000$ & $\$ 7,227,000$ & $-44 \%$ & $-\$ 5,600,000$ \\
\hline DRC & $\$ 64,670,000$ & $\$ 50,000,000$ & $\$ 35,453,000$ & $-45 \%$ & $-\$ 29,217,000$ \\
\hline Burundi & $\$ 11,099,000$ & $\$ 10,000,000$ & $\$ 5,791,000$ & $-48 \%$ & $-\$ 5,308,000$ \\
\hline Ghana & $\$ 7,680,000$ & $\$ 15,000,000$ & $\$ 3,836,000$ & $-50 \%$ & $-\$ 3,844,000$ \\
\hline Ethiopia & $\$ 141,812,000$ & $\$ 100,000,000$ & $\$ 69,358,000$ & $-51 \%$ & $-\$ 72,454,000$ \\
\hline Papua New Guinea & $\$ 5,858,000$ & $\$ 2,000,000$ & $\$ 2,679,000$ & $-54 \%$ & $-\$ 3,179,000$ \\
\hline Angola & $\$ 15,448,000$ & $\$ 10,000,000$ & $\$ 5,756,000$ & $-63 \%$ & $-\$ 9,692,000$ \\
\hline Cambodia & $\$ 10,031,000$ & $\$ 5,000,000$ & $\$ 3,691,000$ & $-63 \%$ & $-\$ 6,340,000$ \\
\hline Myanmar & $\$ 8,493,000$ & $\$ 5,000,000$ & $\$ 2,986,000$ & $-65 \%$ & $-\$ 5,507,000$ \\
\hline India & $\$ 15,708,000$ & $\$ 10,000,000$ & $\$ 5,311,000$ & $-66 \%$ & $-\$ 10,397,000$ \\
\hline Ukraine & $\$ 31,615,000$ & $\$ 30,000,000$ & $\$ 10,264,000$ & $-68 \%$ & $-\$ 21,351,000$ \\
\hline Indonesia & $\$ 8,616,000$ & $\$ 7,500,000$ & $\$ 2,742,000$ & $-68 \%$ & $-\$ 5,874,000$ \\
\hline
\end{tabular}

Sources: State FY2019 Congressional Budget Justification; PEPFAR FY2018 Congressional Budget Justification Supplement.

Note: Totals were manually extracted from PDFs. Any errors in extraction are my own. 
Table 10 shows the current cohort of bilateral PEPFAR programs, separated by acceleration and non-acceleration groupings and ranked by fiscal dependence on PEPFAR funding.

Across both groups, the absolute size of PEPFAR disbursements is striking, as is the level of PEPFAR dependence among at least a subset of countries. The top seven recipients of PEPFAR financing each receive over $\$ 200$ million a year, and the next three largest recipients each receive over $\$ 100$ million. These allocations loom large relative to government general expenditure on health-more than 100 percent in Haiti, Uganda, and Mozambique, and 50 percent or more in an additional five countries.

Disaggregating by acceleration status, clear difference between the groups emerge. On average, the subset of acceleration countries receives substantially more absolute funding than the subset of non-acceleration funding. (Mean annual spend for acceleration countries: $\$ 147.2$ million; range: $\$ 35.8$ million [Lesotho] to $\$ 418.8$ million [Kenya]. Mean spend for non-acceleration countries: $\$ 78.5$ million; range: $\$ 4.6$ million [Papua New Guinea] to $\$ 399.8$ million [South Africa]). With the notable exception of Mozambique, the acceleration countries also tend to be more dependent on PEPFAR financing, with PEPFAR spend equal to an average of 46.9 percent of government health expenditure in the acceleration group (range: 6.1 percent [Namibia] to 136.9 percent [Haiti]), compared to 14.2 percent in the non-acceleration group (range: 0.1 percent [Indonesia] to 143.4 percent [Mozambique]).

\section{Table 10. PEPFAR Acceleration and Non-Acceleration Countries}

\section{Acceleration Countries}

\begin{tabular}{lcc}
\hline & $\begin{array}{c}\text { Annual (2016) } \\
\text { Expenditure }\end{array}$ & $\begin{array}{c}\text { As \% of } \\
\text { GGHE-D } \\
\mathbf{( 2 0 1 5 )}\end{array}$ \\
\hline Haiti & $\$ 87,602,940$ & $136.9 \%$ \\
Uganda & $\$ 283,696,043$ & $106.9 \%$ \\
Zambia & $\$ 239,757,769$ & $57.9 \%$ \\
Rwanda & $\$ 76,610,980$ & $55.0 \%$ \\
Malawi & $\$ 90,039,566$ & $52.8 \%$ \\
Kenya & $\$ 418,843,101$ & $38.0 \%$ \\
Tanzania & $\$ 339,254,103$ & $34.4 \%$ \\
Zimbabwe & $\$ 108,715,016$ & $31.0 \%$ \\
Lesotho & $\$ 35,847,915$ & $30.1 \%$ \\
Côte d'Ivoire & $\$ 101,868,625$ & $25.9 \%$ \\
Swaziland & $\$ 45,143,492$ & $24.6 \%$ \\
Botswana & $\$ 47,312,666$ & $10.0 \%$ \\
Namibia & $\$ 39,690,924$ & $6.1 \%$
\end{tabular}

Non-Acceleration Countries

\begin{tabular}{lcc} 
& $\begin{array}{c}\text { Annual (2016) } \\
\text { Expenditure }\end{array}$ & $\begin{array}{c}\text { As \% of } \\
\text { GGHE-D } \\
\mathbf{( 2 0 1 5 )}\end{array}$ \\
\hline Mozambique & $\$ 233,351,503$ & $143.4 \%$ \\
South Sudan & $\$ 11,204,535$ & $23.2 \%$ \\
Ethiopia & $\$ 154,145,918$ & $22.0 \%$ \\
DRC & $\$ 48,079,955$ & $18.0 \%$ \\
Nigeria & $\$ 386,613,867$ & $13.6 \%$ \\
Cameroon & $\$ 29,519,913$ & $12.9 \%$ \\
Burundi & $\$ 9,424,830$ & $9.6 \%$ \\
Cambodia & $\$ 8,348,558$ & $3.4 \%$ \\
South Africa & $\$ 399,755,835$ & $2.9 \%$ \\
Myanmar & $\$ 6,992,990$ & $1.0 \%$ \\
Angola & $\$ 14,435,129$ & $1.0 \%$ \\
Vietnam & $\$ 43,138,264$ & $0.9 \%$ \\
Ghana & $\$ 7,102,096$ & $0.9 \%$ \\
Papua New Guinea & $\$ 4,653,678$ & $0.8 \%$ \\
Ukraine & $\$ 21,193,674$ & $0.8 \%$ \\
Dominican Republic & $\$ 10,086,156$ & $0.6 \%$ \\
Indonesia & $\$ 8,744,364$ & $0.1 \%$ \\
India & $\$ 15,368,218$ & $0.1 \%$ \\
& &
\end{tabular}


Nonetheless, many countries in the non-acceleration group could be fiscally vulnerable to reductions in PEPFAR financing, whether from reallocation of funding or overall cuts to the PEPFAR portfolio. Several of these countries receive hundreds of millions in dedicated funding per year from PEPFAR, and in six countries PEPFAR financing sums to 10 percent or more of GGHE-D. Mozambique emerges as particularly vulnerable, with PEPFAR financing totaling 143.4 percent of GGHE-D. Other countries with less extreme vulnerability - for example Nigeria, South Sudan, and the Democratic Republic of the Congo-may face PEPFAR funding draw-downs simultaneously with other drops in external funding for the health sector. We explore the issue of simultaneous transitions in the next section.

\section{Results: Transition Interactions, Sequencing, and Risk}

In the previous section, I looked at the projected transition patterns for each individual mechanism. Here, I consider the sequencing and interactions across all projected transitions at the country level. (A full database, including all mechanisms and across all countries, is included as an online appendix.)

First, I wish to identify the subset of countries with a high overall fiscal burden from anticipated transitions; that is, those countries that are likely to see major drops in funding across all mechanisms during any given time period. For the purposes of this section, a "transition" from one mechanism includes the following:

- Entering a period of transition funding or graduation for one or more Global Fund disease areas.

- Entering "full self-financing" for Gavi.

- Entering a period of non-acceleration for PEPFAR (only applies to 2017-2020)

- All countries that currently receive GPEI funding (applies to 2017-2021)

- Countries that are at risk of IDA graduation, defined here as those that have been above the threshold for 5 to 10 years and are not small island economies, or those that are small island economies and are projected to become HICs.

A country is defined as "high-risk" from transitions if (1) the country is undergoing one or more transitions during the same period, or with a one-year gap; and (2) the total annualized funding from those transitioning mechanisms exceeds 10 percent of GGHE-D. A country is defined as "moderate risk" if the combined value of those mechanisms exceeds 5 percent of GGHE-D but sums to less than 10 percent of GGHE-D; OR if it less than 5 percent but above 2.5 percent of GGHE-D AND includes an IDA transition, whose fiscal impacts we are unable to quantify here. Otherwise, it is defined as low risk.

Based on these criteria, 11 countries are categorized as at high fiscal risk from transition. Table 11 presents the set of these countries, including all projected transitions therein within 
the analysis timeframe, the corresponding total fiscal impact, and the time-period of highest risk. A few points stand out. First, six of these "high-risk" countries are vulnerable to PEPFAR non-acceleration and eight countries will be affected by GPEI winddown; five countries will be affected by simultaneous PEPFAR non-acceleration and GPEI withdrawal. Second, six of these countries will undergo Gavi transition during this time-period; however, only three will begin GAVI transition by 2025. Third, Gavi and IDA transitions are both determined by income per capita, with relatively similar thresholds. (The IDA threshold is somewhat lower, but there is typically a lag of several years between crossing the threshold and losing IDA eligibility). As a result, the timing for Gavi and IDA transitions typically overlaps. Fourth, none of the "high-risk" countries are projected to transition from Global Fund support at any point during this time-period. Fifth, with the partial exceptions of Nigeria and Pakistan, these are not countries necessarily considered as "transitioning"; they generally have very low GDP per capita and weak health systems. Finally, the period of highest risk appears to be in the immediate future, from 2017-2022 for most countries. This is largely driven by the concentrated period of GPEI winddown paired with potential implications of PEPFAR non-acceleration in a subset of countries, both occurring in the near future. 
Table 11. Countries at High Fiscal Risk from Global Health Transitions, 2015-2040

\begin{tabular}{|c|c|c|c|c|c|c|c|c|c|c|c|c|c|c|c|c|c|c|c|c|c|c|c|c|c|c|c|}
\hline Country & Funding Mechanism & $\stackrel{\stackrel{n}{\sigma}}{\sim}$ & & & & ฏ & & & & & $\stackrel{\stackrel{\sim}{ٍ}}{\sim}$ & & & & ஜ & & & & 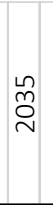 & & & & ণ্ণ & $\begin{array}{c}\text { As \% of } \\
\text { GGHE-D } \\
(2015)\end{array}$ & $\begin{array}{c}\text { Total } \\
\text { (Simultaneous } \\
\text { Transitions) as } \\
\text { \% of GGHE-D } \\
\text { (2015) }\end{array}$ & Simultaneous Transitions & $\begin{array}{l}\text { Highest Risk } \\
\text { Period }\end{array}$ \\
\hline Afghanistan & GPEI & & & $T$ & $T T$ & $T T$ & $T T$ & & & & 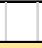 & 1 & L & & 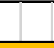 & 1 & & 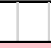 & 1 & & & & 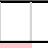 & $85.1 \%$ & $85.1 \%$ & & $2017-2022$ \\
\hline \multirow{4}{*}{ Cameroon } & Gavi & P & P & P & P F & P P & $P$ P & $\mathrm{P}$ & P & P & P & P & P & ATA & ATAT & TATF & AT G & $G \mathrm{G}$ & $\mathrm{GC}$ & G $G$ & $\mathrm{G} G$ & G & G & $3.5 \%$ & \multirow{4}{*}{$17.1 \%$} & \multirow{4}{*}{ IDA, GPEI, PEPFAR } & \multirow{4}{*}{ 2017-2022 } \\
\hline & GPEI & & & T & T $T$ & T $T$ & T $\mathrm{T}$ & & & & & & & & & & 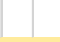 & & & & & & 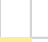 & $4.2 \%$ & & & \\
\hline & IDA & 0 & 0 & 0 & $\mathrm{OC}$ & $\mathrm{OC}$ & 00 & 0 & 0 & 0 & 0 & $\mathrm{O}$ & $\mathrm{OC}$ & 00 & 0 & $\mathrm{OCC}$ & 00 & 0 & OC & $\mathrm{OC}$ & 0 & $\mathrm{OC}$ & O & & & & \\
\hline & PEPFAR & & & D & $\mathrm{D}$ & $\mathrm{D} D$ & & & & & & & L & & 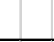 & & & & & & & & & $12.9 \%$ & & & \\
\hline Chad & GPEI & & & $T$ & $T T$ & $T T$ & $\mathrm{~T} T$ & & & & & 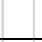 & 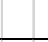 & & & & & & & & 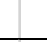 & & 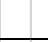 & $15.6 \%$ & $15.6 \%$ & & \\
\hline \multirow{2}{*}{ DRC } & GPEI & & & $\mathrm{T}$ & $T T$ & $T T$ & T $\mathrm{T}$ & & & 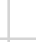 & 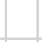 & & 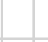 & & & 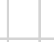 & & & & & & & 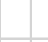 & $11.8 \%$ & \multirow{2}{*}{$29.8 \%$} & \multirow{2}{*}{ GPEI, PEPFAR } & \multirow{2}{*}{ 2017-2022 } \\
\hline & PEPFAR & & & D & $\mathrm{D}$ & $D D$ & & & 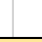 & 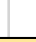 & 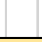 & 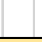 & 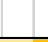 & & 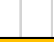 & & & & 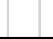 & 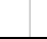 & & & 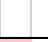 & $18.0 \%$ & & & \\
\hline \multirow{2}{*}{ Eritrea } & Gavi & $E$ & E & E & E P & P P & $P P$ & P & $P$ & $P$ & $P$ & P & $P A$ & AT A $^{-}$ & AT AT & TAT A & AT G & $5 \mathrm{G}$ & $\mathrm{GC}$ & G $\mathrm{C}$ & $G G$ & $G G$ & G & $19.0 \%$ & \multirow{2}{*}{$19.0 \%$} & \multirow{2}{*}{ Gavi, IDA } & \multirow{2}{*}{ 2027-2035 } \\
\hline & IDA & U & u & U & U L & U & U 0 & 0 & 0 & 0 & 0 & 0 & $0 \mathrm{C}$ & 00 & 00 & $0 \mathrm{c}$ & 00 & 00 & $\mathrm{OC}$ & 00 & 00 & 00 & 0 & & & & \\
\hline \multirow{4}{*}{ Ethiopia } & Gavi & $E$ & E & E & E E & E P & $P P$ & $\mathrm{P}$ & $P$ & $P$ & P & P & P P & $P P$ & $P$ & P $A$ & $\mathrm{AT}^{-}$ & AT AT & TAT A & AT G & G G & $G G$ & G & $9.1 \%$ & \multirow{4}{*}{$24.0 \%$} & \multirow{4}{*}{ GPEI, PEPFAR } & \multirow{4}{*}{ 2017-2022 } \\
\hline & GPEI & & & T & T $T$ & T T & T $\mathrm{T}$ & & & & & & 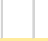 & & & & & & & & & & & $2.0 \%$ & & & \\
\hline & IDA & u & u & U & U & U u & U U & U & 10 & 0 & 0 & 0 & $\mathrm{OC}$ & 00 & 00 & $\mathrm{OC}$ & 00 & 00 & OC & $\mathrm{OC}$ & 00 & $0 \mathrm{C}$ & 0 & & & & \\
\hline & PEPFAR & & & D & $\mathrm{D}$ & $\mathrm{D} D$ & & & & & & & 1 & & H & 1 & & & L & & & & & $22.0 \%$ & & & \\
\hline Mozambique & PEPFAR & 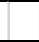 & & $\mathrm{D}$ & $\mathrm{D}$ & 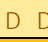 & & & 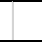 & 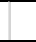 & 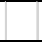 & 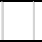 & 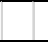 & 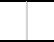 & 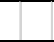 & 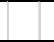 & 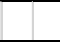 & F & 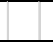 & 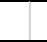 & 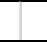 & 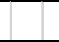 & 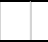 & $143.4 \%$ & $143.4 \%$ & & $2017-2020$ \\
\hline \multirow{4}{*}{ Nigeria } & Gavi & P & $P$ & AT & FAT F & ATA & AT A & G & $G$ & G & G & G & GC & G G & $G G$ & $\mathrm{GC}$ & G G & G G & GC & G G & G G & G G & G & $3.8 \%$ & \multirow{4}{*}{$24.8 \%$} & \multirow{4}{*}{ Gavi, GPEI, PEPFAR, IDA } & \multirow{4}{*}{ 2017-2021 } \\
\hline & GPEI & & & T & T T & T T & $T T$ & & & & & & $t$ & & a & 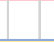 & & 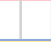 & & & & 植 & 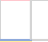 & $7.4 \%$ & & & \\
\hline & IDA & 0 & 0 & 0 & $\mathrm{OC}$ & $\mathrm{OC}$ & 00 & 0 & 0 & 0 & 0 & $\mathrm{O}$ & $\mathrm{OC}$ & 00 & 00 & $\mathrm{OC}$ & 00 & 00 & $\mathrm{OC}$ & O C & 00 & $\mathrm{OC}^{\circ}$ & 0 & & & & \\
\hline & PEPFAR & & & D & $\mathrm{D}$ & $\mathrm{D} D$ & & & & & & & + & & 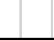 & L & 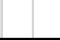 & 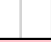 & L & - & {$[+$} & 1 & & $13.6 \%$ & & & \\
\hline \multirow{3}{*}{ Pakistan } & Gavi & P & P & P & $P F$ & $P \quad P$ & P $P$ & A & TAT & $T A$ & TAT & AT & G & G G & G G & GC & G G & G G & $\mathrm{GC}$ & G $G$ & G G & G G & G & $5.8 \%$ & \multirow{3}{*}{$16.7 \%$} & & \\
\hline & GPEI & & & T & T $T$ & T T & T $\mathrm{T}$ & & & & & & & & & & & & & & & & & $11.0 \%$ & & Gavi, GPEI, IDA & 2017-2027 \\
\hline & IDA & 0 & 0 & 0 & $\mathrm{OC}$ & 00 & 00 & $\mathrm{O}$ & 0 & 0 & 0 & 0 & 00 & 00 & 00 & $\mathrm{OC}$ & 00 & 00 & $\mathrm{OC}$ & $0 \mathrm{C}$ & 00 & $\mathrm{OCO}$ & 0 & & & & \\
\hline Sao Tome \& Principe & Gavi & $P$ & $\mathrm{P}$ & $P$ & $\mathrm{PA}$ & $A A$ & $\mathrm{AA}$ & $\mathrm{A}$ & $A$ & G & $\mathrm{G}$ & $\mathrm{G}$ & $\mathrm{GC}$ & $\mathrm{GG}$ & $\mathrm{GG}$ & $\mathrm{GC}$ & G G & $\mathrm{GG}$ & $\mathrm{GC}$ & $\mathrm{GC}$ & $G G$ & $\mathrm{GC}$ & & $13.1 \%$ & $13.1 \%$ & & $2019-2023$ \\
\hline South Sudan & GPEI & & & T & T $T$ & T T & $\mathrm{T} T$ & & & & & & & & & & & & & & & & & $33.8 \%$ & $57.0 \%$ & GPEI, PEPFAR & $2017-2022$ \\
\hline soutn sudan & PEPFAR & & & D & $\mathrm{D}$ & D D & & & & & & & & & & & & & & & & & & $23.2 \%$ & (51.0\% & & \\
\hline
\end{tabular}

Notes: Gavi: Green “E”: eligible. Yellow "P”: “Preparatory Transition.” Orange “A”: “Accelerated Transition.” Red "G”: graduated/Fully Self-Financing. PEPFAR: Green “A”:

Acceleration. Yellow “D”: Non-Acceleration IDA: Green "U”: eligible, under threshold. Green "I”: eligible, small island economy. Green "O”: eligible, over threshold. Yellow “O”: over threshold, unknown eligibility. Red “G”: graduated. Global Fund: Green “E”: eligible. Yellow “T”': transition funding. Red "G”: graduated. GPEI: Yellow “T”: Transitioning. 
Table 12. Countries at Moderate Fiscal Risk from Global Health Transitions, 2015-2040

\begin{tabular}{|c|c|c|c|c|c|c|c|c|c|c|c|c|c|c|c|c|c|c|c|c|c|c|c|c|c|c|c|c|c|}
\hline Country & Funding Mechanism & $\stackrel{n}{\circ}$ & & & & & Оి & & & & & 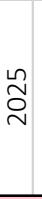 & & & & & 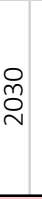 & & & & 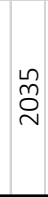 & & & & ㅇํ & $\begin{array}{c}\text { As \% of } \\
\text { GGHE-D } \\
(2015)\end{array}$ & \begin{tabular}{|c|} 
Total \\
(Simultaneous \\
Transitions) as \% \\
of GGHE-D \\
$(2015)$ \\
\end{tabular} & Simultaneous Transitions & $\begin{array}{l}\text { Highest } \\
\text { Risk Period }\end{array}$ \\
\hline \multirow{4}{*}{ Bangladesh } & Gavi & $E$ & $P$ & $P$ & $\bar{P}$ & $P$ & A & $\bar{A}$ & $\bar{A}$ & $\bar{A}$ & A & G & G & $\mathrm{G}$ & $\mathrm{G}$ & $G$ & $\mathrm{G}$ & G & $\overline{G G}$ & $G$ & $G$ & G & $\overline{G G}$ & $G$ & G & $8.9 \%$ & \multirow{4}{*}{$9.2 \%$} & \multirow{4}{*}{ IDA, Gavi, GPEI } & \multirow{4}{*}{ 2017-2025 } \\
\hline & GFATM: HIV & E & $E$ & $E$ & E & $E$ & E & $\mathrm{E}$ & $\mathrm{E}$ & $\mathrm{E}$ & $E$ & E & $E$ & E & E & E E & E & E & $E \quad E$ & $E$ & $T$ & $\mathrm{~T}$ & $T \quad G$ & $G$ & G & $0.8 \%$ & & & \\
\hline & GPEI & & & $\mathrm{T}$ & T & $T$ & $T$ & T & & & & & & & & & & & & & & & & & & $0.3 \%$ & & & \\
\hline & IDA & 0 & 0 & 0 & 0 & 0 & 0 & 0 & 0 & 0 & 0 & 0 & 0 & 0 & 0 & $\mathrm{OCO}$ & 0 & 0 & 00 & 0 & 0 & 0 & 00 & 0 & 0 & & & & \\
\hline Burundi & PEPFAR & 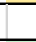 & T & $\mathrm{D}$ & $\mathrm{D}$ & $\mathrm{D}$ & $\mathrm{D}$ & & 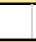 & 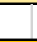 & 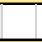 & 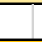 & 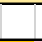 & 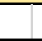 & 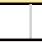 & 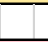 & 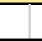 & 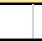 & 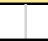 & 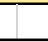 & 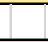 & 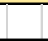 & 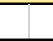 & 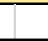 & 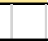 & $9.6 \%$ & $9.6 \%$ & & 2017-2022 \\
\hline \multirow{3}{*}{ Cambodia } & Gavi & $\mathrm{E}$ & $P$ & $P$ & 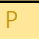 & $P$ & $\mathrm{P}$ & $\mathrm{P}$ & A & A & A & A & A & G & G & G C & G & G & G G & $G$ & G & G & G G & $G$ & G & $4.5 \%$ & \multirow{3}{*}{$4.5 \%$} & \multirow{3}{*}{ Gavi, IDA } & \multirow{3}{*}{ 2017-2027 } \\
\hline & IDA & U & 0 & $\mathrm{O}$ & O & 0 & 0 & O & 0 & O & 0 & O & 0 & O & O & $\mathrm{OCC}$ & O & O & 00 & 0 & 0 & 0 & 00 & 0 & 0 & & & & \\
\hline & PEPFAR & & & D & D & D & D & & & & & & 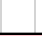 & 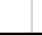 & 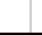 & 1 & 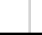 & 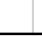 & 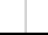 & 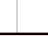 & 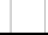 & 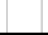 & 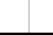 & 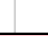 & 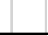 & $3.4 \%$ & & & \\
\hline \multirow{2}{*}{ Côte d'Ivoire } & Gavi & $P$ & $P$ & $P$ & $P$ & $P$ & A & A & A & $\bar{A}$ & $A$ & $\bar{G}$ & $\mathrm{G}$ & $\bar{G}$ & $\bar{G}$ & $\overline{G C}$ & $\overline{\mathrm{G}}$ & $\bar{G}$ & $\overline{G G}$ & $G$ & $G$ & G & $\overline{G G}$ & $G$ & $G$ & $9.9 \%$ & \multirow{2}{*}{$9.9 \%$} & \multirow{2}{*}{ Gavi, IDA } & \multirow{2}{*}{ 2021-2025 } \\
\hline & IDA & 0 & 0 & 0 & 0 & 0 & 0 & 0 & 0 & 0 & 0 & 0 & 0 & 0 & 0 & 0 & 0 & 0 & 00 & 0 & 0 & 0 & 00 & 0 & 0 & & & & \\
\hline \multirow{3}{*}{ Lao P.D.R. } & Gavi & $P$ & $P$ & $A$ & $A$ & $A$ & $A$ & $\bar{A}$ & $\bar{G}$ & $\bar{G}$ & $G$ & $\bar{G}$ & $G$ & $\bar{G}$ & $\bar{G}$ & $\overline{G C}$ & $\bar{G}$ & $\mathrm{G}$ & $\overline{\mathrm{G} \mathrm{G}}$ & $G$ & $\mathrm{G}$ & G & $\overline{G G}$ & $G$ & $\mathrm{G}$ & $3.0 \%$ & \multirow{3}{*}{$3.0 \%$} & \multirow{3}{*}{ Gavi, IDA } & \multirow{3}{*}{ 2017-2022 } \\
\hline & GFATM: HIV & E & $E$ & E & E & E & $\mathrm{E}$ & $E$ & $E$ & E & $\mathrm{E}$ & E & $\mathrm{E}$ & E & E & E E & E & E & T $T$ & $T$ & G & G & G G & $G$ & G & $1.7 \%$ & & & \\
\hline & IDA & 0 & 0 & 0 & 0 & 0 & 0 & 0 & 0 & 0 & 0 & $\mathrm{O}$ & 0 & 0 & 0 & $\mathrm{OCO}$ & 0 & O & 00 & 0 & 0 & 0 & 00 & 0 & 0 & & & & \\
\hline \multirow{4}{*}{ Myanmar } & Gavi & $\bar{E}$ & $P$ & $\bar{P}$ & $\mathrm{P}$ & $\bar{P}$ & $P$ & $\bar{A}$ & $\bar{A}$ & $\bar{A}$ & $A$ & A & G & $\bar{G}$ & $\bar{G}$ & $\overline{G C}$ & $\bar{G}$ & $\mathrm{G}$ & $\overline{\mathrm{G} G}$ & $G$ & $\bar{G}$ & G & $\overline{G G}$ & $G$ & $\mathrm{G}$ & $3.4 \%$ & \multirow{4}{*}{$3.4 \%$} & \multirow{4}{*}{ PEPFAR + GPEI; Gavi+IDA } & \multirow{4}{*}{ 2017-2028 } \\
\hline & GPEI & & & T & T & T & T & T & & & & & & & & & & & & & & & & & & $0.3 \%$ & & & \\
\hline & IDA & U & 0 & 0 & 0 & 0 & 0 & 0 & 0 & 0 & 0 & O & 0 & O & O & OC & O & O & 00 & 0 & 0 & 0 & 00 & 0 & 0 & & & & \\
\hline & PEPFAR & & & D & D & D & D & & & & & 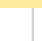 & 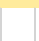 & & 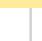 & 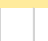 & & & 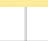 & 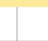 & 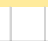 & 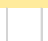 & & & 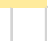 & $1.0 \%$ & & & \\
\hline \multirow{3}{*}{ Nepal } & Gavi & $E$ & $E$ & $\bar{E}$ & $\bar{E}$ & $\bar{E}$ & $\mathrm{E}$ & $\bar{P}$ & $\bar{P}$ & $\bar{P}$ & $P$ & $P$ & $\bar{P}$ & $P$ & $P$ & $\overline{P F}$ & $P$ & $P$ & $\overline{A A}$ & $A$ & $A$ & A & $\overline{G G}$ & $G$ & $\mathrm{G}$ & $3.0 \%$ & & & \\
\hline & GPEI & & & T & T & T & T & T & & & $1-1$ & 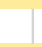 & 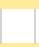 & & 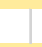 & & & & 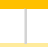 & 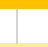 & & 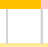 & 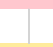 & 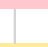 & 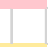 & $0.8 \%$ & $3.0 \%$ & Gavi, IDA & 2031-2036 \\
\hline & IDA & U & U & U & U & U & $\mathrm{U}$ & U & U & 0 & 0 & 0 & 0 & $\mathrm{O}$ & 0 & $\mathrm{OCO}$ & 0 & 0 & 00 & 0 & 0 & 0 & 00 & 0 & 0 & & & & \\
\hline Senegal & Gavi & $E$ & $E$ & $\bar{E}$ & $\bar{P}$ & $\bar{P}$ & $P$ & $P$ & $\bar{P}$ & $\bar{P}$ & $P$ & $P$ & $\bar{P}$ & $P$ & $\mathrm{P}$ & $\overline{P P}$ & $\overline{P r}$ & A & $\overline{A A}$ & $A$ & $A$ & G & $\overline{\mathrm{G} \mathrm{G}}$ & $G$ & $\mathrm{G}$ & $6.4 \%$ & $6.4 \%$ & & \\
\hline senegal & IDA & U & U & $u$ & U & U & U & 0 & 0 & 0 & 0 & O & 0 & 0 & 0 & $\mathrm{OCO}$ & 0 & 0 & 00 & 0 & 0 & 0 & 00 & 0 & 0 & & $\%$ & & $2031-2035$ \\
\hline & Gavi & $E$ & $E$ & $P$ & $P$ & $P$ & $P$ & $P$ & $P$ & $\bar{P}$ & $P$ & $P$ & $P$ & A & A & $\overline{A A}$ & $A$ & A & $\mathrm{G} \mathrm{G}$ & $G$ & $G$ & $\mathrm{G}$ & $\overline{\mathrm{G} \mathrm{G}}$ & $G$ & $G$ & $4.1 \%$ & 4 1\% & & \\
\hline I anzanıa & IDA & U & U & U & U & 0 & 0 & 0 & 0 & 0 & 0 & 0 & 0 & 0 & 0 & 0 & 0 & 0 & 00 & 0 & 0 & 0 & $0 \quad 0$ & 0 & 0 & & $4.1 \%$ & Gavı, IDA & $2021-2031$ \\
\hline & Gavi & A & $A$ & A & G & $G$ & G & $\mathrm{G}$ & $\mathrm{G}$ & $\mathrm{G}$ & $\mathrm{G}$ & $\mathrm{G}$ & $\mathrm{G}$ & $\mathrm{G}$ & $\mathrm{G}$ & $\overline{G C}$ & $\mathrm{G}$ & $\mathrm{G}$ & $\overline{\mathrm{G} \mathrm{G}}$ & $G$ & $\mathrm{G}$ & $G$ & $\overline{\mathrm{GG}}$ & $G$ & $G$ & $8.4 \%$ & & & \\
\hline $11 \mathrm{~m}$ & IDA & 0 & 0 & 0 & 0 & 0 & 0 & 0 & 0 & 0 & 0 & O & 0 & 0 & & 0 & & & 00 & 0 & 0 & 0 & 00 & 0 & 0 & & 8 & & 24 \\
\hline
\end{tabular}

Notes: Gavi: Green "E”: eligible. Yellow "P”: "Preparatory Transition.” Orange "A”: “Accelerated Transition.” Red "G”: graduated/Fully Self-Financing. PEPFAR: Green "A":

Acceleration. Yellow "D": Non-Acceleration IDA: Green "U”: eligible, under threshold. Green "I": eligible, small island economy. Green "O”: eligible, over threshold. Yellow "O”: over threshold, unknown eligibility. Red “G”: graduated. Global Fund: Green "E”: eligible. Yellow “T”': transition funding. Red "G”: graduated. GPEI: Yellow “T”: Transitioning. 
An additional 10 countries are categorized as "moderate risk" (Table 12). This cohort more closely resembles the common understanding of transitioning countries, including Bangladesh, Cambodia, Myanmar, Senegal, and Tanzania. There are some early high-risk periods driven by PEPFAR, GPEI, Gavi, and IDA transitions, but other high-risk periods occur later in the analysis period, for example 2031-2035 for Senegal or 2027-2031 for Tanzania—both driven by projected Gavi graduation.

In general, looking across all mechanisms, a relatively clear sequencing of transition emerges. GPEI transitions are expected in the near future regardless of country characteristics; the GPEI would in a sense be a victim of its own success vis-à-vis its eradication mandate, putting itself out of business. Gavi and IDA transitions often overlap, occurring relatively early in a country's economic development. PEPFAR transitions are difficult to predict, but major changes could be coming in the very near future for the subset of countries not designated as acceleration countries in the most recent PEPFAR strategy. (Notably, most countries put at risk by PEPFAR non-acceleration have indeed seen reductions in requested funding between 2017 and FY2019; see Table 9). Global Fund transitions, in contrast, tend to come far later in the course of a country's economic development, often many decades after a country loses eligibility for other sources of global health financing.

\section{Discussion}

This paper has set out to map projected global health transitions through 2040; quantify the absolute and relative fiscal impact of projected transitions at the country level; and draw lessons about the near- and medium-term prognosis for large global health financing mechanisms. Working from explicit eligibility policies set by Gavi, the Global Fund, and IDA, as well as anticipated financing changes from GPEI and PEPFAR, this paper has mapped and quantified the impact of each mechanism's approach to transition. Under current eligibility criteria, it has shown that Gavi and IDA will each see major transformations of their funding portfolios by 2040, while few large or aid-dependent countries will transition from Global Fund financing before 2040. The timing of PEPFAR transition is difficult to predict; given the absolute size of PEPFAR disbursements and the concentration of financing in a handful of countries, even minor funding cuts or reallocations among countries could have significant fiscal implications at the country level. Finally, this paper has shown that the countries in most fiscal jeopardy from anticipated transition are not the countries typically conceptualized as "transitioning" based on GDP per capita or disease burden, but instead those that are likely to be impacted by the imminent wind down of GPEI and reallocations of PEPFAR financing - neither of which is directly related to a country's capacity to finance its own health system with domestic funds. A handful of countries, particularly Nigeria, face many major transitions within a very narrow time window-and the cumulative fiscal effect is substantial, even if each individual transition should be manageable. All underlying data and analysis, including a complete database of projected transitions, are shared as an online appendix.

Importantly, this analysis is affected by several significant limitations, discussed previously but comprehensively summarized here. First, the GDP per capita projections are crude, reflecting an assumption of constant growth rates through 2040. This is of course unlikely to 
precisely reflect reality but offers an indicative growth path to inform planning. Second, the analysis does not account, country-by-country, for individual conversations and exceptions that may be put in place at the country level. It attempts to reconcile projected results with actual reported eligibility status during the period of analysis, but there may yet be some discrepancies. Third, given the lack of reliable, universal disease projections, the Global Fund results may be overly conservative or overly optimistic. I attempt to provide a sensitivity analysis by rerunning the results under a more optimistic assumption about future disease burden, but this too does not account for differential rates of progress at the country levelor, conversely, the possibility that disease burden could worsen, at least in individual countries. Fourth, the analysis is not an exhaustive catalogue of all global health aid transitions that might affect countries; it does not include, for example, direct support received from UNICEF, UNFPA, DFID, the Bill \& Melinda Gates Foundation, or USAID (including the President's Malaria Initiative). Finally, the calculations of government expenditure on health — and therefore my estimates of fiscal burden — should be considered rough, indicative estimates at best. The data is several years old (2015) and may not reflect the current health financing landscape-or future increases in domestic expenditure on health driven by economic growth or increased fiscal prioritization. Because of these limitations, the projections here should be understood as indicative estimates to help inform planning, not hard and fast predictions.

Despite the major limitations of this analysis, the indicative results raise several important questions for global health funding mechanisms and the bilateral donors that support them. Mapping across all funding sources, versus a vertical, ring-fenced approach for each mechanism, helps present a clearer picture of overall fiscal and programmatic stress likely to be caused by upcoming transitions. The funding mechanisms with relatively well-defined transition policies (Gavi, the Global Fund, and IDA) have a relatively minor projected fiscal impact compared to mechanisms with no explicit eligibility policy and the prospect of major near-term funding changes (GPEI and PEPFAR).

GPEI emerges as a particularly important source of near-term fiscal and programmatic stress. This finding is hardly new; potential risks of GPEI transition (including simultaneous transitions with Gavi and IDA) have previously been highlighted by RESULTS 46 and ACTION, ${ }^{47}$ as well as by the GPEI itself. The GPEI's strategic plan for 2013-2018 highlights "legacy planning"-including the transition of polio "assets and infrastructure"as one of four main objectives. To support and monitor this process, the GPEI also set up its own Transition Independent Monitoring Board (TIMB) — a mechanism mandated to "independently monitor and guide the process of polio transition planning." ${ }^{48}$ The TIMB's most recent report, issued in November 2017, strikes a notably pessimistic tone about the

\footnotetext{
${ }^{46}$ Laura Kerr and Leila Stennett, "A Balancing Act: risks and opportunities as polio and its funding disappears," Results, 13 November 2017, http://www.results.org.au/wp-content/uploads/2017/11/FINAL-Balancing-Act.pdf.

${ }^{47}$ Heather Teixeira et al., "Progress in Peril? The Changing Landscape of Global Health Financing," Action Global Health Advocacy Partnership, 19 September 2017, http://www.action.org/uploads/documents/Progress in Peril web updated 103017.pdf.

48 "Polio Transition Independent Monitoring Board: Terms of Reference," Global Polio Eradication Initiative, http://polioeradication.org/wp-content/uploads/2016/08/TIMB TOR.pdf.
} 
prospect for successful transition-particularly the impending fiscal gap among donors and countries alike:

At this point, some of the key data needed to understand potential funding and health service delivery gaps are uncollected or do not seem to be openly available. For example, it is not clear what the impact of health service cuts that have already been made are in the African Region. There are no detailed plans from Gavi, the Vaccine Alliance (Gavi), and the Measles \& Rubella Initiative yet about how the loss of polio funding will affect their programmes. Other impact assessments do not seem to be available, such as the loss of vitamin A delivery, reductions in bed nets and scaling down of health camps. A degree of denial has played a part in slowing the planning process. Many countries affected by the funding loss have not yet come to terms with the reality of its withdrawal. Neither have some of the key organisations that have benefited from polio funding over the years. The transition planning process has unsettled some traditional donors. They are wary of countries establishing a market stall of potential health services at which donors are expected to shop. Few donors are prepared to engage with the GPEI planners as brokers seeking funding for country service-need shortfalls. They prefer to engage through bilateral discussions with countries in the context of their existing commitments and programmes of aid.

With PEPFAR, the absolute size of disbursements at the country level is striking - and the relatively high levels of fiscal dependence on PEPFAR funds create a baseline level of high risk for all countries receiving PEPFAR support. PEPFAR lacks an explicit eligibility policy, making it difficult for countries to anticipate and prepare for programmatic and fiscal impacts of eventual PEPFAR transition. In addition, the recent selection of acceleration countries implies non-acceleration elsewhere, where even small reallocations can translate to very large fiscal effects — and data from 2017 and 2019 suggests that this designation may indeed drive large reallocations of funding between PEPFAR countries, at least if budget cuts were to be realized. In addition, given the recent US political situation and the lack of high-level predictability for PEPFAR financing in the out years, maintenance of current budget levels cannot be taken for granted even in the immediate future. Across the PEPFAR portfolio, recipient countries should be proactive in developing contingency plans that could be deployed in the event of sudden shifts or withdrawals in PEPFAR support.

For Gavi, the acceleration in transition between 2015 and 2020 will present a major stresstest of its aggressive transition approach. Gavi graduation is based almost exclusively on national income, without direct consideration of vaccination coverage rates in countries receiving its support. As a result, many countries are poised to graduate despite stubbornly low vaccination coverage. (They will, however, continue to access relatively low Gavi prices in the immediate aftermath of transition.) The Medicins Sans Frontieres Access Campaign recently criticized Gavi's growth-exclusive eligibility policy, arguing that "measures of immunization coverage should factor into eligibility and transition decisions for all Gavi countries." As is, MSF raised alarm that 20 countries were poised to transition from Gavi support by 2020 — what they described as a "funding cliff" — suggesting that "current rules 
fail to protect all children against killer diseases." ${ }^{49}$ As illustrated in this paper, and previously flagged by ACTION, ${ }^{50}$ the risk is compounded by frequent simultaneous transitions with GPEI — an alternative large source of immunization financing — and IDA—a source of concessional financing to governments writ large. The cumulative effect of these three transitions could be a fiscal crunch directly affecting vaccination expenditure in countries that still have not achieved sufficiently high vaccination coverage.

For its part, Gavi has signaled openness toward "flexibility" in at least some settings. For example, Nigeria is currently projected to fully transition from Gavi in 2021. Nonetheless, Gavi CEO Seth Berkley recently told a local Nigerian newspaper that Gavi might be open to continued support past 2021 - if and only if the Nigerian government demonstrates "commitment" and "improvement" in its immunization program. ${ }^{51}$ Referencing the article on twitter, Berkley commented: "unfortunately, hard measures are necessary to get strong commitment to do the right thing for Nigeria's children," 52 suggesting that Gavi's stance was one of "tough love." Yet this position — an openness to continued financing beyond the formal end of the eligibility period-represents a relaxation of the existing rules, rather than a more stringent set of co-financing requirements. Given Nigeria's uniquely difficult position over the next several years, with four anticipated transitions and a cumulatively high fiscal burden, it may be appropriate to afford the country an additional cycle of vaccination support. Yet if the Nigeria government and other countries perceive low domestic spending and poor performance will extend the duration of Gavi support, there is also the risk of moral hazard—which could potentially undermine transition efforts across the Gavi portfolio.

The relatively strict Gavi eligibility criteria, and consequent wealth of projected transitions by 2040, contrasts with the relatively inclusive Global Fund policy and slow pace of Global Fund transitions. It is not clear that donors understand the Global Fund's long-term funding requirements under current eligibility criteria—even under the optimistic "universal progress scenario - or that they will continue to fund future replenishments in sufficient quantities to support the projected portfolio of countries into the medium- to long-term future. If not, countries will necessarily see their allocations shrink substantially, and there is a risk that at least some countries will be pushed to transition well before the anticipated moment under the current eligibility policy.

The findings across global health mechanisms also highlight the Global Fund's predicament vis-à-vis its efforts to increase country co-financing for its three disease areas. Savvy

\footnotetext{
${ }^{49}$ Nathalie Ernoult, "20 countries about to fall off Gavi funding 'cliff,' risking their ability to pay for life-saving vaccines for children long term,” MSF Access Campaign, 28 November 2017, https://www.msfaccess.org/aboutus/media-room/press-releases/20-countries-about-fall-Gavi-funding-0 $\%$ E2 $\% 80 \% 98$ cliff $\% \mathrm{E} 2 \% 80 \% 99$-riskingtheir.

${ }^{50}$ Heather Teixeira et al., "Progress in Peril? The Changing Landscape of Global Health Financing," Action Global Health Advocacy Partnership, 19 September 2017, http://www.action.org/uploads/documents/Progress in Peril web updated 103017.pdf.

${ }^{51}$ Judd-Leonard Okafor, "GAVI window closing, unimmunised children on the line," Daily Trust, 8 March 2018, https://www.dailytrust.com.ng/Gavi-window-closing-unimmunised-children-on-the-line.html.

52 Seth Berkley's full tweet can be accessed at https://twitter.com/GaviSeth/status/972013591493795840.
} 
countries will account for the broader demands placed upon their health systems by the entire range of projected transitions, and fiscally prioritize those that are most urgent and impactful. As Global Fund transitions are typically in the distant future, countries may rationally elect to prioritize domestic funding for vaccination or routine surveillance gaps caused by GPEI withdrawal. This effect may be partially mitigated by the Global Fund's cofinancing policy, which requires countries to make a certain level of domestic investment to access their entire allocations ${ }^{53}$ - but they may also choose to forego the Global Fund "incentive financing" comprising about 15 percent of their allocation, or to co-finance the bare minimum required to access the entire allocation. Further, it is difficult to track the extent to which Global Fund co-financing requirements add to countries' overall fiscal burden from transition (now and in the future), as these requirements are typically negotiated directly with countries under the broad auspices of the Sustainability, Transition, and CoFinancing Policy. ${ }^{54}$ The process by which these negotiations take place, and the outcome of the negotiations in terms of country-by-country co-financing requirements, remains mostly opaque to external observers. The extent of the co-financing requirements often only become clear if they are not met, as with the recent "de-commitment" of $\$ 170.6$ million from Nigeria's 2014-2016 allocation. 55

\section{Recommendations and Conclusion}

The findings of this analysis suggest two major recommendations for global health policymakers. First, instead of focusing narrowly on managing their own disease-specific transitions, global health funders should work cooperatively with countries to better understand the sequencing and magnitude of transitions, drawing on country-specific fiscal and programmatic context and more precise data than was used for this indicative analysis. The analysis presented herein was conducted entirely based on publicly available data, but a better version could almost certainly be done for each individual country with access to proprietary data sources, particularly for long-term GDP growth and disease trends. For example, one could imagine a publicly accessible dashboard incorporating up-to-date disease projections (possibly from the Institute for Health Metrics and Evaluation), economic growth forecasts, and data on current co-financing requirements for each country and disease area. Data could be submitted by countries and major funders using pre-agreed data fields, and then collated and validated by a third-party portal manager.

Second, upcoming replenishments for Gavi, the Global Fund, and IDA represent an opportunity for bilateral donors - many of whom contribute to all three mechanisms and sit on their governing boards - to revisit eligibility policies and attempt to craft a more coherent global approach. There may well be good reasons to maintain different timelines for

\footnotetext{
53 “The Global Fund Sustainability, Transition and Co-financing Policy," The Global Fund, April 2016, https://www.theglobalfund.org/media/4221/bm35 04-sustainabilitytransitionandcofinancing_policy en.pdf. 54 “The Global Fund Sustainability, Transition and Co-financing Policy," The Global Fund, April 2016, https://www.theglobalfund.org/media/4221/bm35 04-sustainabilitytransitionandcofinancing_policy en.pdf. 55 David Garmaise, “Global Fund chops \$170.6 million from Nigeria’s 2014-2016 allocation,” Aidspan, 21 March 2018, http://aidspan.org/gfo article/global-fund-chops-1706-million-nigeria $\%$ E2\%80\%99s2014\%E2\%80\%932016-allocation.
} 
transition between mechanisms (e.g. vaccination is a universal, low-cost intervention, vs. HIV treatment as high-cost and targeted to relatively small populations, but such decisions should be made with an eye toward their global implications.

In total, this analysis helps map anticipated global health transitions over the next two decades, illuminating the long-term global implications of different transition approaches across several global health financing mechanisms. While imperfect, the indicative results should help provide rough guidance to countries about when transition processes will commence, and the fiscal burdens they must be prepared to assume. Global health donors should build upon these results, working cooperatively at the country level, to ensure countries have a realistic understanding of transition processes and timing to enable appropriate planning, budgeting, and prioritization. 


\section{Appendices}

Appendix 1: Relationship Between GNI per Capita and GDP per Capita (Current \$US), LMICs

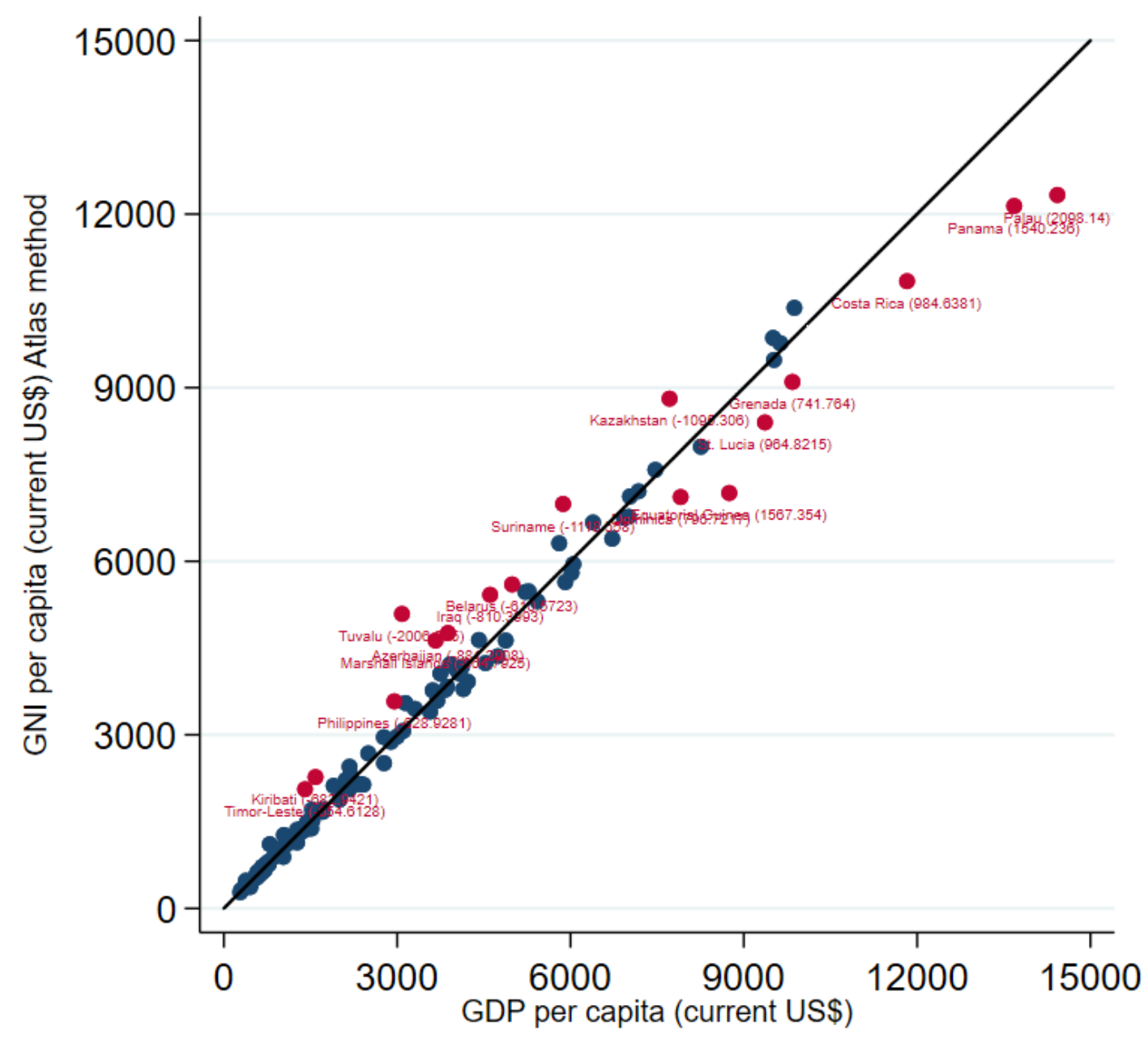

Source: World Development Indicators 


\section{Appendix 2: Global Fund Disease Burden Categories Under Previous Eligibility Policy ${ }^{56}$}

\begin{tabular}{|c|c|c|c|}
\hline & $\mathrm{HIV}^{*}$ & TB $^{*}$ & MALARIA* * \\
\hline Category & $\begin{array}{l}\text { HIV prevalence in population } \\
\text { and/or key populations }\end{array}$ & $\begin{array}{l}\text { Combination of TB notification rate per } \\
100,000 \text { population (all forms including } \\
\text { relapses); and add WHO list of high } \\
\text { burden countries (TB, TB/HIV or MDR- } \\
\text { TB burden) }\end{array}$ & $\begin{array}{l}\text { Combination of mortality per } 1000 \text { at risk of } \\
\text { malaria; morbidity rate per } 1000 \text { at risk; and } \\
\text { contribution to global deaths attributable to } \\
\text { malaria. }\end{array}$ \\
\hline Extreme & HIV national prevalence $\geq 10 \%$ & $\begin{array}{l}\text { TB notification rate per } 100,000 \geq 300 \text { and } \\
\text { high TB, TB/HIV or MDR-TB burden } \\
\text { country }\end{array}$ & $\begin{array}{l}\text { Mortality rate } \geq 2 \text { OR Contribution to global deaths } \\
\geq 2.5 \%\end{array}$ \\
\hline Severe & $\begin{array}{l}\text { HIV national prevalence } \geq 2 \% \\
\text { and }<10 \%\end{array}$ & $\begin{array}{l}\text { TB notification rate per } 100,000 \text { of } \geq 100 \S \\
\text { OR TB notification rate } \geq 50 \text { and }<100 \\
\text { and high TB, TB/HIV or MDR-TB burden } \\
\text { country }\end{array}$ & $\begin{array}{l}\text { Mortality rate } \geq 0.75^{\S} \text { and morbidity rate } \geq 10 \mathrm{OR} \\
\text { Contribution to global deaths } \geq 1 \% \S \text { OR country } \\
\text { with documented artemisinin resistance }\end{array}$ \\
\hline High & $\begin{array}{l}\text { HIV national prevalence } \geq 1 \% \\
\text { and }<2 \% \text { OR prevalence in a } \\
\text { key population } \geq 5 \%\end{array}$ & $\begin{array}{l}\text { TB notification rate per } 100,000 \text { of } \geq 50 \\
\text { and }<100 \text { OR TB notification rate per } \\
100,000 \geq 20 \text { and }<50 \text { and high TB, } \\
\text { TB/HIV or MDR-TB burden country }\end{array}$ & $\begin{array}{l}\text { Mortality rate } \geq 0.75 \text { and morbidity rate }<10 \text { OR } \\
\text { mortality rate } \geq 0.1 \text { and }<0.75 \text { regardless of } \\
\text { morbidity rate } \mathbf{O R} \text { contribution to global deaths } \\
\geq 0.25 \% \text { and }<1 \%\end{array}$ \\
\hline Moderate & $\begin{array}{l}\text { HIV national prevalence } \geq \\
0.5 \% \text { and }<1 \% \text { OR prevalence } \\
\text { in a key population } \geq 2.5 \% \text { and } \\
<5 \%\end{array}$ & $\begin{array}{l}\text { TB notification rate per } 100,000 \text { of } \geq 20 \\
\text { and }<50 \text { OR TB notification rate per } \\
100,000<20 \text { and high TB, TB/HIV or } \\
\text { MDR-TB burden country }\end{array}$ & $\begin{array}{l}\text { Mortality rate }<0.1 \text { and morbidity rate } \geq 1 \mathrm{OR} \\
\text { contribution to global deaths } \geq 0.01 \% \text { and }<0.25 \%\end{array}$ \\
\hline Low & $\begin{array}{l}\text { HIV national prevalence < } \\
0.5 \% \text { and prevalence in a key } \\
\text { population } \\
<2.5 \% \text { OR no data }\end{array}$ & $\begin{array}{l}\text { TB notification rate per } 100,000 \text { of }<20 \\
\text { OR no data }\end{array}$ & $\begin{array}{l}\text { Mortality rate }<0.1 \text { and morbidity rate }<1 \mathrm{OR} \\
\text { contribution }<0.01 \% \text { OR no data }\end{array}$ \\
\hline
\end{tabular}

56 "The Global Fund Eligibility Policy," The Global Fund, April 2016,

https://www.theglobalfund.org/media/4227/bm35 06-eligibility policy en.pdf. 


\section{Appendix 3: Projected Gavi Transitions 2015-2040, Ranked by Aggregate Gavi Disbursements (2017)}

\begin{tabular}{|c|c|c|c|c|c|c|c|c|c|c|c|c|c|c|c|c|c|}
\hline Country & $\begin{array}{l}\stackrel{\sim}{2} \\
\stackrel{\overbrace{}}{N}\end{array}$ & & & & ঠి & & & 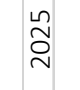 & & & 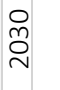 & & 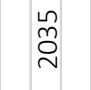 & & P & 2017 Disbursements & $\begin{array}{c}\text { As \% of GGHE-D } \\
\text { (2015) }\end{array}$ \\
\hline India & $b$ & $P F$ & $P$ & & A A A & 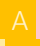 & G & G G G & $\mathrm{G} G$ & G G & G G & G G & G G G & $G \mathrm{G} \mathrm{G}$ & G G G & $\$ 149,505,531$ & $0.7 \%$ \\
\hline Pakistan & $P$ & P F & $P F$ & $P P$ & $P P P$ & & A & A A A & & G G & G G & G G & G G G & $G \mathrm{GG}$ & G G G & $\$ 115,138,076$ & $5.8 \%$ \\
\hline Nigeria & $P$ & $P$ & A & A A & $A$ A A & G & G & G G G & G & G G & G G & G G & G G G & $G G G$ & $G G G$ & $\$ 109,071,924$ & $4 \%$ \\
\hline Bangladesh & $E$ & $P F$ & $P F$ & $P P$ & $P A A$ & & A & $A G G$ & & G G & G G & G G & $G G G$ & $G \mathrm{GG}$ & $G$ G G & $\$ 67,075,861$ & $8.9 \%$ \\
\hline Ethiopia & $E$ & $\mathrm{E} \mathrm{E}$ & E & $E E$ & E P P & $P$ & $P$ & $P P P$ & $\mathrm{P}$ & $P P F$ & $P P$ & A A & $A A A$ & $A G$ & $G \mathrm{G} \mathrm{G}$ & $\$ 63,776,700$ & $9.1 \%$ \\
\hline Tanzania & $E$ & E P & $P F$ & $P$ P & $P P P$ & $P$ & $P$ & $P P P$ & A & A A & A A & G G & G G G & $G \mathrm{G} \mathrm{G}$ & $G$ G G & $\$ 40,235,603$ & $4.1 \%$ \\
\hline Côte d'Ivoire & $P$ & $P F$ & $P F$ & $P P$ & $P A A$ & A & A & $A G G$ & & G G & G G & G G & G G G & G G G & $G$ G G & $\$ 39,073,165$ & $9.9 \%$ \\
\hline Indonesia & A & $A C$ & G & G G & G G G & G & G & G G G & $G$ & G G & & G G & G G G & $G G$ & $G G G$ & $\$ 35,290,409$ & $0 \%$ \\
\hline Kenya & $E$ & $P F$ & $P F$ & $P A$ & A A A & A & A & G G G & G & G G & G G & G G & G G G & G G G & 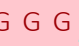 & $\$ 24,823,663$ & $2.3 \%$ \\
\hline Myanmar & $E$ & $P F$ & $P$ & $P$ P & $P P A$ & A & A & $A$ A G & G & G G C & G G & G G & G G G & G G G & $G$ G G & $\$ 22,894,630$ & $3.4 \%$ \\
\hline Sudan & $P$ & $P F$ & $P$ & $P A$ & $A$ A A & A & A & G G G & G & G G C & G G & G G & G G G & $G G$ & $G$ G G & $\$ 21,575,749$ & $1.1 \%$ \\
\hline Ghana & $E$ & $P F$ & $P$ & $P P$ & $P A A$ & A & A & $A G G$ & & G G C & G G & G G & G G G & $5 \mathrm{GG}$ & G G G & $\$ 15,626,492$ & $2.0 \%$ \\
\hline Zimbabwe & $E$ & E P & $P$ & $P P$ & $P P P$ & $P$ & P & $P P P$ & $\mathrm{P}$ & P P P & $P P$ & $P P$ & $P P P$ & $P A$ & $A$ A A & $\$ 15,127,625$ & $4 \%$ \\
\hline Zambia & $P$ & P F & $P$ & $P$ P & $P P P$ & $P$ & P & A A A & $A$ & $A G C$ & G G & G G & G G G & $G \mathrm{G} \mathrm{G}$ & G G G & $\$ 12,417,325$ & $3.0 \%$ \\
\hline Senegal & $E$ & E E & E & $P P$ & $P P P$ & $\mathrm{P}$ & $P$ & $P P P$ & $\mathrm{P}$ & P P P & $P A$ & $A A$ & $A A G$ & G G G & $G G G$ & $\$ 10,996,945$ & $6.4 \%$ \\
\hline Cambodia & $E$ & P F & $P$ & P P & $P P P$ & A & A & A A A & G & G G C & G G & G G & G G G & G G G & $G$ G G & $\$ 10,838,495$ & $4.5 \%$ \\
\hline Angola & A & A $A$ & A & G G & G G G & G & G & G G G & G & G G C & G G & G G & G G G & $G \mathrm{GC}$ & $G \mathrm{G} \mathrm{G}$ & $\$ 10,088,927$ & $1 \%$ \\
\hline Cameroon & $P$ & $P F$ & $P$ & $P P$ & $P P P$ & $P$ & $P$ & $P$ P P & $P$ & $A A A$ & A A & $A G$ & $G G G$ & $G \mathrm{G} \mathrm{G}$ & $\mathrm{G} \mathrm{G} \mathrm{G}$ & $\$ 7,922,614$ & $3.5 \%$ \\
\hline Benin & E & $\mathrm{E} \mathrm{E}$ & E & $E E$ & $E E E$ & $P$ & $P$ & $P P P$ & $\mathrm{P}$ & P P P & $P P$ & $\mathrm{PP}$ & $P P P$ & $P A$ & $A$ A A & $\$ 7,582,630$ & $11 \%$ \\
\hline Nepal & $E$ & E E & E & $E E$ & $E$ E P & $P$ & $P$ & $P P P$ & $P$ & P P P & P P & A A & $A A A$ & $A G$ & $G$ G G & $\$ 7,170,534$ & $3.0 \%$ \\
\hline Lao P.D.R. & $P$ & $P F$ & A & A A & A A A & G & & G G G & G & G G C & G G & G G & G G G & $\mathrm{GG} \mathrm{G}$ & G G G & $\$ 4,247,638$ & $3 \%$ \\
\hline Eritrea & $E$ & E E & E & EP & $P P P$ & $P$ & P & $P P P$ & $P$ & A A A & A A & $A G$ & G G G & G G & G G G & $\$ 3,764,487$ & $19.0 \%$ \\
\hline Kyrgyz Republic & $P$ & $P F$ & $P$ & $P P$ & $P P P$ & $P$ & $P$ & $P P P$ & $\mathrm{P}$ & P P P & $P A$ & $A A$ & $A A G$ & G G & $G$ G G & $\$ 3,415,785$ & $1.4 \%$ \\
\hline Papua New Guinea & $\mathrm{P}$ & A $A$ & A & A A & $A$ A G & G & G & G G G & G & G G C & G G & G G & G G G & G G & G G G & $\$ 3,399,742$ & $1 \%$ \\
\hline Bolivia & 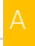 & A $A$ & & G G & G G G & G & & G G G & G & G G C & G G & G G & G G G & G G & $G$ G G & $\$ 3,165,619$ & $0 \%$ \\
\hline Vietnam & $t$ & A $A$ & A & A A & $A G G$ & G & & G G G & G & G G C & G G & G G & G G G & G G & $G$ G G & $\$ 2,843,464$ & $0 \%$ \\
\hline Timor-Leste & $t$ & A $A$ & A & G G & G G G & G & G & G G G & G & G G C & G G & G G & G G G & G G & $G$ G G & $\$ 2,613,246$ & $8 \%$ \\
\hline Sri Lanka & $A$ & $\mathrm{GC}$ & G & G G & G G G & G & G & G G G & G & G G C & G G & G G & G G G & G G & G G G & $\$ 1,786,323$ & $0 \%$ \\
\hline Republic of Congo & A & Af & A & G G & G G G & G & & G G G & G & G G C & G G & G G & G G G & G G & G G G & $\$ 1,699,912$ & $1 \%$ \\
\hline Sao Tome and Principe & $\mathrm{P}$ & $P F$ & $P$ & $P A$ & A A A & A & & G G G & G & G G C & G G & G G & G G G & G G & G G G & $\$ 1,515,216$ & $13.1 \%$ \\
\hline Uzbekistan & A & A $A$ & A & A A & $A G G$ & G & & G G G & G & G G C & G G & G G & G G G & G G & $G$ G G & $\$ 1,034,762$ & $0 \%$ \\
\hline Nicaragua & $P$ & A $A$ & A & A A & $A$ A G & G & & G G G & G & G G C & G G & G G & G G G & G G & G G G & $\$ 915,733$ & $0 \%$ \\
\hline Lesotho & $P$ & $P F$ & $\mathrm{P}$ & $P P$ & $P P P$ & $P$ & P & A A A & $A$ & $A G G$ & G G & G G & G G G & G G & $G \mathrm{G} \mathrm{G}$ & $\$ 904,871$ & $0.8 \%$ \\
\hline Djibouti & P & $\mathrm{PF}$ & P & $P A$ & $A$ A A & A & & G G G & G & G G G & G G & G G & G G G & G G & G G G & $\$ 856,362$ & $2.1 \%$ \\
\hline Azerbaijan & 1 & A $A$ & A & G G & G G G & G & & G G G & G & G G G & G G & G G & G G G & G G & $G$ G G & $\$ 834,407$ & $0 \%$ \\
\hline Armenia & 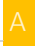 & A & A & G G & G G G & G & & G G G & G & G G G & G G & G G & G G G & G G & $G G G$ & $\$ 571,275$ & $0 \%$ \\
\hline Moldova & & $A C$ & G & G G & G G G & G & G & G G G & G & G G G & G G & G G & G G G & G G & G G G & $\$ 458,254$ & $0 \%$ \\
\hline Georgia & A & A $A$ & & G G & G G G & G & & G G G & G & G G G & G G & G G & G G G & G G & 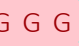 & $\$ 425,270$ & $0 \%$ \\
\hline Solomon Islands & $P$ & P & A & A A & $A$ A A & A & G & G G G & G & G G G & G G & G G & G G G & G G & $G$ G G & $\$ 423,846$ & $1 \%$ \\
\hline Guyana & & $A C$ & G & G G & G G G & G & G & G G G & G & G G G & G G & G G & G G G & G G & $G$ G G & $\$ 178,500$ & $0 \%$ \\
\hline Honduras & & $\mathrm{GC}$ & G & G $\mathrm{G}$ & G G G & G & G & G G G & G & G G G & G G & G G & G G G & G G & 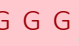 & $\$ 43,042$ & $0 \%$ \\
\hline Bhutan & & GC & & G C & G G G & G & & G G G & G & G G G & G G & G G & G G G & G G & $G G G$ & $\$ 39,312$ & $0 \%$ \\
\hline Mongolia & & GC & & & G G G & G & & G G G & & G G G & G G & G G & G G G & G G & G G G & $\$ 1,698$ & $0 \%$ \\
\hline Kiribati & & $\mathrm{AC}$ & G & G G & G G G & $\mathrm{G}$ & G & G G G & $\mathrm{GG}$ & G G G & G G & G G & G G G & G G & $\mathrm{GG} \mathrm{G}$ & $\$ 0$ & $0 \%$ \\
\hline
\end{tabular}

Notes: Green "E”: eligible. Yellow "P”: "Preparatory Transition.” Orange “A”: “Accelerated Transition.” Red "G": graduated/Fully Self-Financing. 


\section{Appendix 4: Remaining Gavi-Eligible Countries, 2040}

\begin{tabular}{|c|c|c|c|c|c|c|c|c|c|c|c|c|c|c|c|c|c|c|c|c|c|c|}
\hline Country & 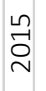 & & & & ญి & & & & 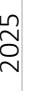 & & & ભૂ & & & & & 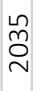 & & & 옹 & 2017 Disbursements & $\begin{array}{c}\text { As \% of GGHE-D } \\
\text { (2015) }\end{array}$ \\
\hline Central African Republic & $\mathrm{E}$ & & $\mathrm{E}$ & $E \mathrm{E}$ & $E$ & $E E$ & $E$ & $E$ & $E E$ & $E$ & E & $E E$ & & $E$ & $P P$ & $P$ & P P & $P$ & $P$ & $P P$ & $\$ 7,301,202$ & $75.6 \%$ \\
\hline Mozambique & E & & E & & $E$ & $E E$ & $E$ & $E$ & $E$ E & $\mathrm{E}$ & E E & $E$ E & & $E$ & $E \mathrm{E}$ & $\mathrm{E}$ & $E$ E & $E$ & E & $E \mathrm{E}$ & $\$ 37,305,378$ & $58.2 \%$ \\
\hline Democratic Republic of the & $=E$ & & $\mathrm{E}$ & $E E$ & $E$ & $E E$ & $E$ & $E$ & $E$ E & $E$ & $\mathrm{E}$ & $E E$ & & $E$ & $E$ E & $\mathrm{E}$ & $E$ E & $E$ & $\mathrm{E}$ & $E E$ & $\$ 84,260,014$ & $31.6 \%$ \\
\hline Afghanistan & E & & $\mathrm{E}$ & $E \mathrm{E}$ & $E$ & $E E$ & $E$ & $E$ & $E$ E & $\mathrm{E}$ & E & $E$ E & & $E$ & E P & $P$ & $P P$ & $\mathrm{P}$ & $P$ & $P P$ & $\$ 25,770,250$ & $25.2 \%$ \\
\hline Niger & $\mathrm{E}$ & & $\mathrm{E}$ & $E \mathrm{E}$ & $E$ & $E E$ & $E$ & $E$ & $E E$ & $E$ & E & E E & & $E$ & $E E$ & E & $E E$ & $E$ & E & $E E$ & $\$ 23,038,450$ & $21.2 \%$ \\
\hline Togo & $\mathrm{E}$ & & E & $E \mathrm{E}$ & $E$ & $E E$ & $E$ & $E$ & $E$ E & $E$ & $E$ & $E E$ & & $E$ & $E E$ & $P$ & $P P$ & $P$ & $\mathrm{P}$ & $P P$ & $\$ 12,146,511$ & $16.0 \%$ \\
\hline South Sudan & E & & $\mathrm{E}$ & E E & $E$ & E E & $E$ & $E$ & $E E$ & $E$ & E E & $E$ & & $E$ & $E \mathrm{E}$ & $\mathrm{E}$ & E E & $E$ & $\mathrm{E}$ & $E E$ & $\$ 7,096,446$ & $14.7 \%$ \\
\hline The Gambia & $\mathrm{E}$ & & $\mathrm{E}$ & $E E$ & $E$ & $E E$ & $E$ & $E$ & $E$ E & $E$ & $\mathrm{E}$ & $E E$ & & $E$ & $E E$ & $\mathrm{E}$ & $E$ E & $E$ & $\mathrm{E}$ & $E E$ & $\$ 3,678,886$ & $12.9 \%$ \\
\hline Mali & E & & $E$ & E E & $E$ & $E E$ & $E$ & E & $E$ E & $P$ & $P F$ & $P P$ & & $P$ & $P P$ & $P$ & $P P$ & $P$ & P & $P P$ & $\$ 15,511,339$ & $12.3 \%$ \\
\hline Liberia & E & & $\mathrm{E}$ & $E$ & $E$ & $E E$ & $E$ & E & $E E$ & $E$ & E E & $E E$ & & $E$ & $E$ & $\mathrm{E}$ & $E E$ & $E$ & E & $P P$ & $\$ 2,692,510$ & $11.8 \%$ \\
\hline Burkina Faso & E & & $E$ & $=E$ & $E$ & $E E$ & $E$ & E & $E$ E & $E$ & $P F$ & $P P$ & & $P$ & $P P$ & $P$ & P P & $\mathrm{P}$ & P & $P P$ & $\$ 17,357,577$ & $10.8 \%$ \\
\hline Rwanda & $\mathrm{E}$ & & $\mathrm{E}$ & $E \mathrm{E}$ & $E$ & E E & $E$ & $E$ & $P P$ & $P$ & $P F$ & $P P$ & & $P$ & $P P$ & $P$ & $P P$ & $P$ & $\mathrm{P}$ & $P P$ & $\$ 14,720,545$ & $10.6 \%$ \\
\hline Uganda & E & & $\mathrm{E}$ & E E & $E$ & $E E$ & $E$ & E & $E$ E & $E$ & $\mathrm{E}$ & $E P$ & & $P$ & $P P$ & $P$ & $P P$ & $P$ & $P F$ & $P P$ & $\$ 26,463,108$ & $10.0 \%$ \\
\hline Yemen & $P F$ & & $P$ & $P P$ & $P$ & $P P$ & $P$ & $P$ & $P P$ & $P$ & $P F$ & $P P$ & & $P$ & $P P$ & $P$ & $P P$ & $\mathrm{P}$ & $\mathrm{P}$ & $P P$ & $\$ 18,715,531$ & $8.1 \%$ \\
\hline Mauritania & $P F$ & & P & $P P$ & $P$ & $P P$ & $P$ & $P$ & $P P$ & $P$ & $P F$ & $P P$ & & $P$ & $P P$ & $\mathrm{P}$ & $P P$ & $P$ & $P$ & $P P$ & $\$ 6,179,228$ & $7.0 \%$ \\
\hline Guinea & E & & $E$ & $E \mathrm{E}$ & $E$ & $E E$ & $E$ & $E$ & $E$ E & $E$ & E & $E$ E & & $E$ & $E E$ & $E$ & $E$ E & $E$ & $E$ & $E E$ & $\$ 4,560,797$ & $6.7 \%$ \\
\hline Sierra Leone & $\mathrm{E}$ & & $\mathrm{E}$ & $E \mathrm{E}$ & $E$ & E E & $E$ & $E$ & E P & $P$ & $P F$ & $P P$ & & $P$ & $P$ & $\mathrm{P}$ & $P P$ & $P$ & $P F$ & $P P$ & $\$ 4,586,201$ & $6.6 \%$ \\
\hline Madagascar & E & & $E$ & E E & $E$ & $E E$ & $E$ & $E$ & $E$ E & $E$ & $\mathrm{E}$ & $E E$ & & & $E E$ & $E$ & $E$ E & $E$ & E & $E E$ & $\$ 13,347,221$ & $5.8 \%$ \\
\hline Burundi & E & & E & $E$ E & $E$ & $E E$ & $E$ & E & $E$ E & $E$ & $\mathrm{E}$ & $E E$ & & $E$ & $E$ & $E$ & E P & $P$ & $P F$ & $P P$ & $\$ 5,581,554$ & $5.7 \%$ \\
\hline Haiti & E & & $\mathrm{E}$ & $E$ E & $E$ & $E E$ & $E$ & E & $E$ E & $E$ & $\mathrm{E}$ & $E E$ & & $E$ & $E \mathrm{E}$ & $E$ & $E \mathrm{E}$ & $E$ & E & $E E$ & $\$ 3,560,368$ & $5.6 \%$ \\
\hline Malawi & $\mathrm{E}$ & & E & & $E$ & $E E$ & $E$ & $E$ & $E$ & $E$ & $\mathrm{E}$ & $E$ & & $E$ & $E$ & $\mathrm{E}$ & $E \mathrm{E}$ & $E$ & $\mathrm{E}$ & $E E$ & $\$ 8,755,849$ & $5.1 \%$ \\
\hline Chad & $E$ & & $\mathrm{E}$ & $E$ E & $E$ & $E E$ & $E$ & $E$ & $E$ E & $E$ & $\mathrm{E}$ & E E & & E & $E$ & $\mathrm{E}$ & $E E$ & $E$ & $\mathrm{E}$ & E P & $\$ 5,644,958$ & $4.8 \%$ \\
\hline Zimbabwe & E & & P & $P P$ & $P$ & $P P$ & $P$ & $P$ & $P P$ & $\mathrm{P}$ & $P F$ & $P P$ & & $P$ & $\mathrm{P}$ & $P$ & $P P$ & $P$ & A & A A & $\$ 15,127,625$ & $4.3 \%$ \\
\hline Guinea-Bissau & E & & $\mathrm{E}$ & $E$ & $E$ & $E E$ & $E$ & $E$ & $E E$ & $E$ & $P F$ & $P P$ & & $P$ & $P P$ & $P$ & $P P$ & $P$ & $\mathrm{P}$ & $P P$ & $\$ 706,850$ & $3.2 \%$ \\
\hline Tajikistan & $E$ & & $\mathrm{E}$ & $E$ E & $E$ & E P & $P$ & $P$ & $P P$ & $\mathrm{P}$ & $P F$ & $P$ P & & $P$ & $\mathrm{P}$ & $P$ & P P & $\mathrm{P}$ & $\mathrm{PF}$ & $P P$ & $\$ 4,730,292$ & $3.1 \%$ \\
\hline Benin & E & & . & & $E$ & EP & $P$ & $P$ & $P P$ & $\mathrm{P}$ & $P F$ & $P P$ & & $P$ & $P$ & $P$ & $P P$ & $P$ & A & A A & $\$ 7,582,630$ & $11.4 \%$ \\
\hline Comoros & E & & $\mathrm{E}$ & E E & $E$ & $E E$ & $E$ & E & E P & $P$ & $\mathrm{PP}$ & $P P$ & 5 & $\mathrm{P}$ & $P P$ & P & $P P$ & $\mathrm{P}$ & $\mathrm{P}$ & $P P$ & $\$ 34,714$ & $0.6 \%$ \\
\hline
\end{tabular}

Notes: Green "E”: eligible. Yellow "P”: "Preparatory Transition.” Orange “A”: “Accelerated Transition.” Red

"G": graduated/Fully Self-Financing. 


\section{Appendix 5a: No Projected GFATM Transitions Among 20 Largest Disease Components (2017 Funding)}

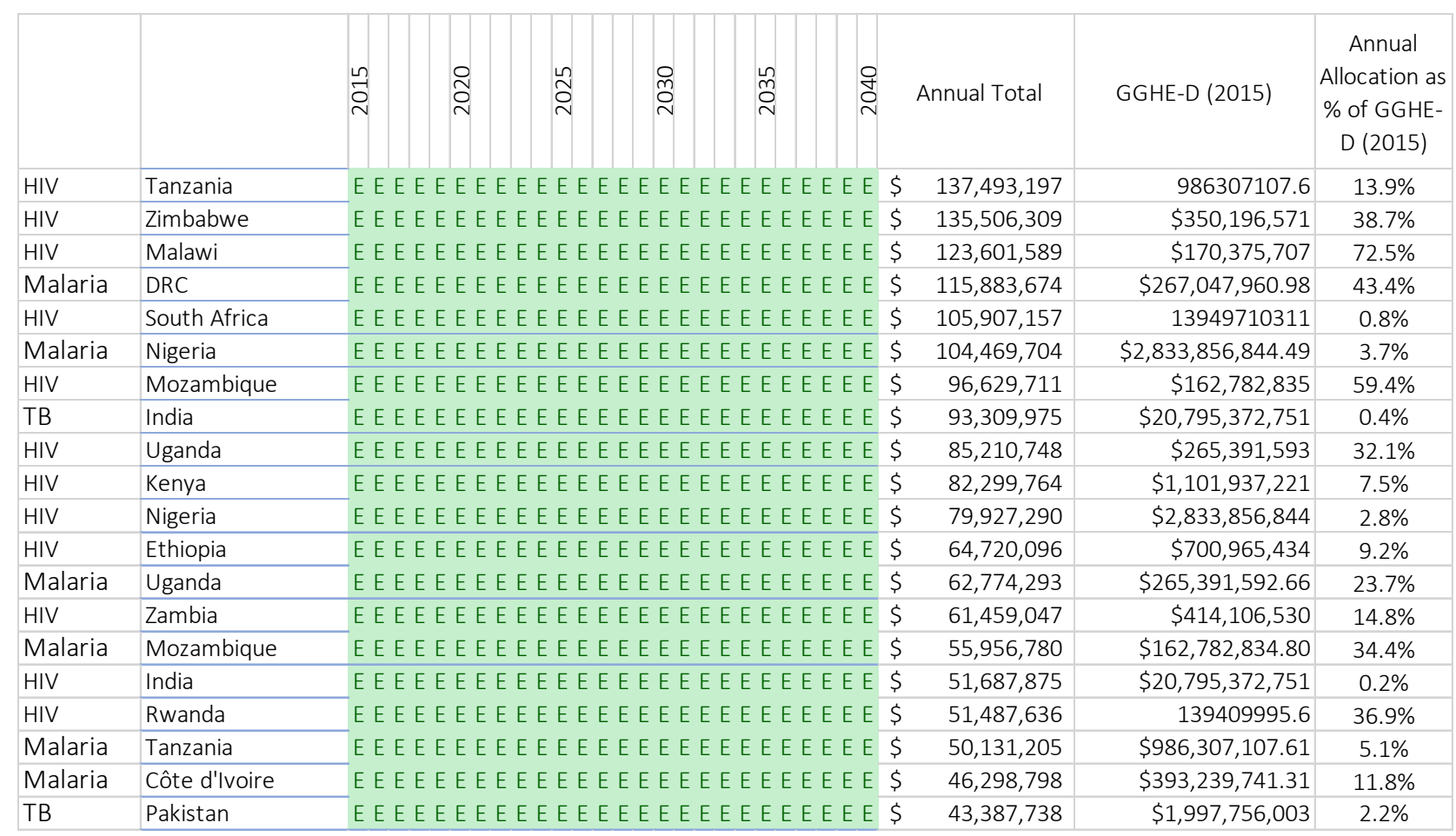

Notes: Green "E”: eligible. Yellow “T”: transition funding. Red "G”: graduated. 


\section{Appendix 5b: No Projected GFATM Transitions Among Most Aid Dependent Countries (2017 Funding)}

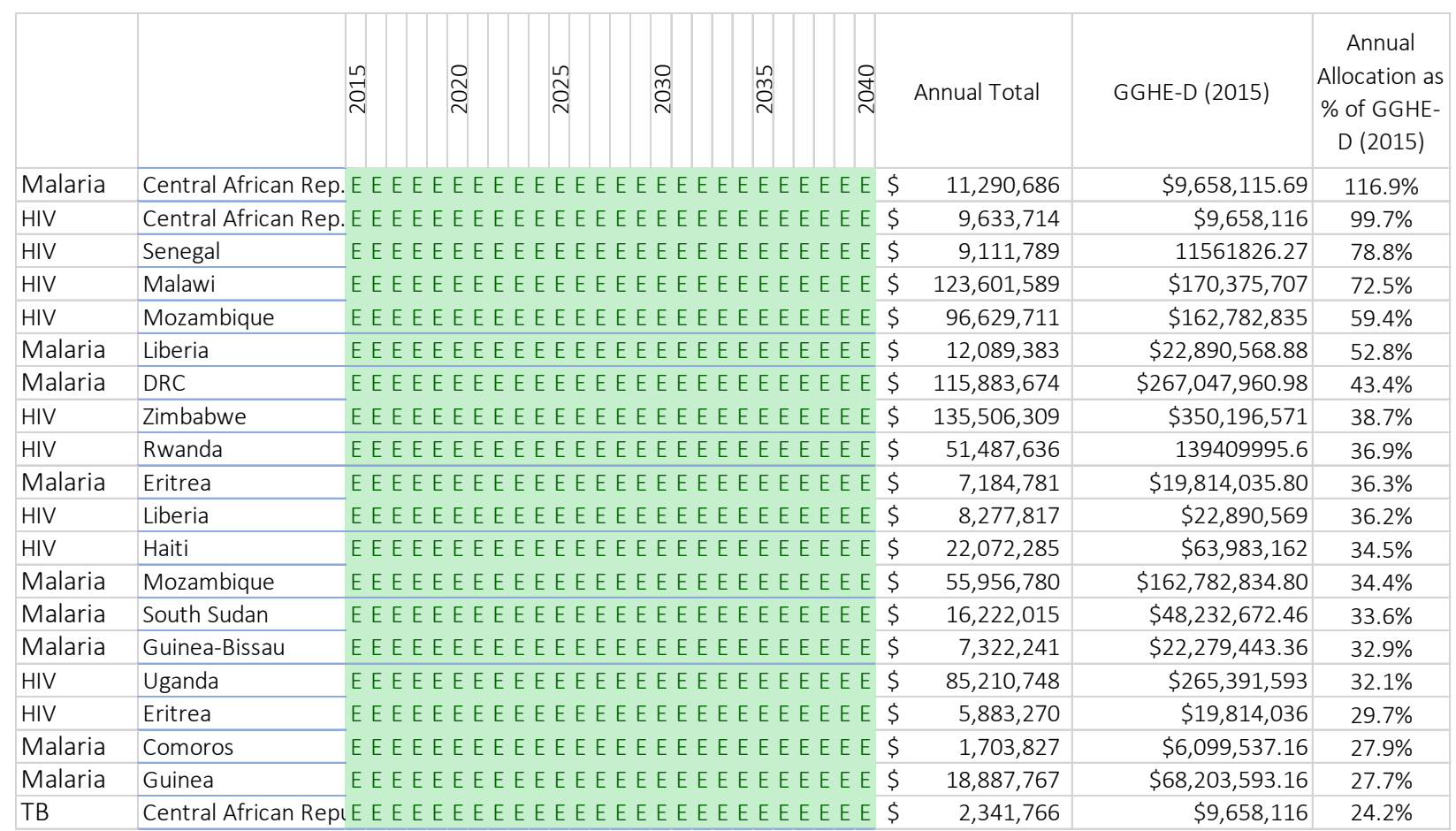

Notes: Green “E”: eligible. Yellow “T”: transition funding. Red "G”: graduated. 


\section{Appendix 6a: Projected Global Fund HIV Transitions 2015-2040-Universal Progress Scenario}

\begin{tabular}{|c|c|c|c|c|c|c|c|c|c|c|}
\hline Country & तึ & 尺઼્ & 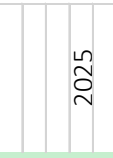 & ஜ্থি & $\stackrel{\stackrel{n}{\tilde{\nu}}}{\stackrel{\nu}{n}}$ & 오 & & Annual Total & GGHE-D (2015) & $\begin{array}{c}\text { Annual } \\
\text { Allocation as } \\
\% \text { of GGHE-D } \\
\text { (2015) }\end{array}$ \\
\hline Myanmar & E E & EEEEE & E E EEE & $E E E E$ & EEETT & $T$ G G G & $\$$ & $41,034,155$ & $\$ 679,492,036$ & $6.0 \%$ \\
\hline Djibouti & E E & $E E E E$ & E E E E & $E E E E E$ & $T T T G G$ & ¿ G G G G & $\$$ & 970,308 & $\$ 41,405,079$ & $2.3 \%$ \\
\hline Guyana & E E & EEEE & E E E E T & $T T G G G$ & s G G G G & G G G G & $\$$ & $1,331,112$ & $\$ 73,704,814$ & $1.8 \%$ \\
\hline Lao P.D.R. & E E & $E E E E$ & E E E E & $E E E E E$ & $T T T G G$ & G G G G & $\$$ & $2,458,032$ & $\$ 142,152,772$ & $1.7 \%$ \\
\hline Armenia & E E & E E ETT & T G G G G & $G$ G G G G & s G G G G & ; G G G & $\$$ & $1,760,927$ & $\$ 170,320,559$ & $1.0 \%$ \\
\hline Moldova & E E & EEEE & EEEE & $=E E E E$ & E E ETT & $\mathrm{T} G \mathrm{GG}$ & $\$$ & $2,977,050$ & $\$ 301,831,281$ & $1.0 \%$ \\
\hline Botswana & E E & $E E E E$ & E E E E & $E E E E E$ & G G G G & G G G G & $\$$ & $4,650,289$ & $\$ 474,767,842$ & $1.0 \%$ \\
\hline Ukraine & E E & EEEE & E E E E T & $T T G G G$ & s G G G G & ; G G G & $\$$ & $23,612,147$ & $\$ 2,591,402,573$ & $0.9 \%$ \\
\hline Bangladesh & E E & EEEE & EEEE & $=E E E E$ & E E ETT & $\mathrm{T} G \mathrm{GG}$ & $\$$ & $6,098,482$ & $\$ 756,697,172$ & $0.8 \%$ \\
\hline Bhutan & E E & $E E E E$ & E T T T G & $\mathrm{G} G \mathrm{GG} \mathrm{G} \mathrm{G}$ & G G G G G & s G G G & $\$$ & 360,634 & $\$ 51,753,931$ & $0.7 \%$ \\
\hline Jamaica & E E & EEEE & E E E E T & $T T$ T G G & s G G G G & ; G G G & $\$$ & $3,310,213$ & $\$ 492,523,407$ & $0.7 \%$ \\
\hline Georgia & E E & EEEE & E E E E T & $T T G G G$ & s G G G G & SGGG & $\$$ & $2,804,329$ & $\$ 430,523,213$ & $0.7 \%$ \\
\hline Belize & $E$ E & $E E E E$ & E E E E T & $T T G G G$ & G G G G G & s G G G & $\$$ & 459,483 & $\$ 71,861,319$ & $0.6 \%$ \\
\hline Guatemala & E E & EEEE & E E E E T & $T T G G G$ & s G G G G & ; G G G & $\$$ & $6,591,109$ & $\$ 1,167,666,072$ & $0.6 \%$ \\
\hline Nicaragua & E E & EEEE & EEEE & $E E E E$ & $T T T G G$ & ¿ G G G & $\$$ & $2,809,994$ & $\$ 562,577,545$ & $0.5 \%$ \\
\hline Mongolia & $E$ E & $E E E E$ & E E E E T & $\Gamma \mathrm{T} T \mathrm{GG}$ & G G G G G & G G G G & $\$$ & $1,014,903$ & $\$ 237,429,173$ & $0.4 \%$ \\
\hline El Salvador & E E & EEEE & E E E E T & $T T G G G$ & s G G G G & ¡ G G G & $\$$ & $4,827,272$ & $\$ 1,156,563,773$ & $0.4 \%$ \\
\hline Vietnam & E E & EEEE & EEEE & $E \mathrm{E} E \mathrm{TTT}$ & G G G G G & G G G G & $\$$ & $18,879,335$ & $\$ 4,56$ & $0.4 \%$ \\
\hline Sudan & E E & E E E T T & T G G G G & $\mathrm{G} G \mathrm{G} \mathrm{G} \mathrm{G} \mathrm{G}$ & G G G G G & G G G G & $\$$ & $6,279,907$ & 1910000045 & $0.3 \%$ \\
\hline Indonesia & E E & E E ETT & T G G G G & $\mathrm{G}$ G G G G G & s G G G G & SGGG & $\$$ & $30,644,854$ & $\$ 9,817,207,164$ & $0.3 \%$ \\
\hline Dominican Republic & E E & EEEE & E E E ET & $T T \mathrm{TGG}$ & S G G G G & sGGG & $\$$ & $5,331,652$ & $\$ 1,710,026,877$ & $0.3 \%$ \\
\hline Azerbaijan & E E & EEEE & E E E E T & $T T G G G$ & s G G G G & ¡ GGG & $\$$ & $2,022,798$ & $\$ 716,818,382$ & $0.3 \%$ \\
\hline Mauritius & E E & EEEE & E G G G G & $\mathrm{G}$ G G G G G & S G G G G & ¿ G G G & $\$$ & 829,306 & $\$ 296,552,465$ & $0.3 \%$ \\
\hline India & E E & EEEEE & E E E E E & $E E E E E$ & T T T GG & ¡ G G G G & $\$$ & $51,687,875$ & $\$ 20,795,372,751$ & $0.2 \%$ \\
\hline Bolivia & E E & EEEE & E E E E T & $T T G G G$ & s G G G G G & SGGG & $\$$ & $3,058,483$ & $\$ 1,438,991,373$ & $0.2 \%$ \\
\hline Morocco & E E & EEEE & E E E E T & $T T G G G$ & s G G G G & s G G G & $\$$ & $4,931,590$ & $\$ 2,421,699,536$ & $0.2 \%$ \\
\hline Sri Lanka & E E & $T T T G G$ & G G G G G & G G G G G G & s G G G G & ; G G G & $\$$ & $2,316,016$ & 1284378681 & $0.2 \%$ \\
\hline Montenegro & E E & EEEE & E E E E T & $T T$ T G G & s G G G G G & G G G G & $\$$ & 232,058 & $\$ 162,473,105$ & $0.1 \%$ \\
\hline Paraguay & $\mathrm{EE}$ & EEEE & E E E E T & $T T G G G$ & s G G G G & ; G G G & $\$$ & $1,477,656$ & $\$ 1,142,133,562$ & $0.1 \%$ \\
\hline Belarus & E E & EEEEE & E E E E T & $T \mathrm{~T} G \mathrm{GG}$ & s G G G G G & ; G G G & $\$$ & $2,620,837$ & $\$ 2,151,695,480$ & $0.1 \%$ \\
\hline Albania & E E & $T T T G G$ & G G G G G & $\mathrm{G}$ G G G G G & s G G G G G & ; G G G & $\$$ & 379,378 & $\$ 327,294,947$ & $0.1 \%$ \\
\hline Tunisia & E E & EEEE & E E E E T & $T T G G G$ & s G G G G & ; G G G & $\$$ & $1,353,352$ & $\$ 1,637,874,639$ & $0.1 \%$ \\
\hline Thailand & E E & EEEE & E E E E T & $T T G G G$ & s G G G G & SGGG & $\$$ & $8,189,717$ & $\$ 11,531,731,877$ & $0.1 \%$ \\
\hline Philippines & $E E$ & EEEEE & E E E E T & $T T G G G$ & s G G G G & s G G G & $\$$ & $2,827,747$ & $\$ 4,057,107,679$ & $0.1 \%$ \\
\hline Ecuador & E E & EEEE & E E E E T & $T T$ T G G & S G G G G & G G G G & $\$$ & $1,776,140$ & $\$ 4,212,918,270$ & $0.0 \%$ \\
\hline Peru & E E & EEEE & E E E E T & $T T G G G$ & s G G G G & ; GGG & $\$$ & $2,088,195$ & $\$ 6,146,248,203$ & $0.0 \%$ \\
\hline Colombia & E E & EEEEE & E E E E T & $T \mathrm{~T}$ GG G & s G G G G & ; G G G & $\$$ & $3,338,194$ & $\$ 12,052,560,537$ & $0.0 \%$ \\
\hline Panama & E E & $E E E G$ & G G G G G & $\mathrm{G}$ G G G G G & s G G G G G & ; G G G & $\$$ & 593,128 & $\$ 2,250,173,008$ & $0.0 \%$ \\
\hline Islamic Repul & I E E & EEEE & E E E E T & $T T G G G$ & s G G G G & s G G G & $\$$ & $3,562,564$ & $\$ 15,645,240,395$ & $0.0 \%$ \\
\hline Serbia & E E & EEEE & E E E ET & $T T G G G$ & s G G G G & G G G G & $\$$ & 457,646 & 2016060037 & $0.0 \%$ \\
\hline Malaysia & E E & EEEE & E G G G & $\mathrm{G}$ G G G G G & S G G G G & ; G G G & $\$$ & $1,343,864$ & $\$ 6,123,080,419$ & $0.0 \%$ \\
\hline Kazakhstan & E E & EEEE & E E E E & G G G G G G & s G G G G & G G G G & $\$$ & 904,741 & $\$ 4,305,796,719$ & $0.0 \%$ \\
\hline Costa Rica & E E & $E E E G$ & G G G G G & $\mathrm{GGGGGG}$ & s G G G G & ; GGG & $\$$ & 706,699 & $\$ 3,393,601,054$ & $0.0 \%$ \\
\hline Algeria & E E & $T T T G G$ & G G G G G & $\mathrm{G}$ G G G G G & s G G G G G & ; G G G & $\$$ & 770,979 & $\$ 8,261,350,514$ & $0.0 \%$ \\
\hline Suriname & E E & EEEEE & E E E E T & $T T \mathrm{TGG}$ & G G G G & s G G G & $\$$ & 270,240 & $\$ 13,949,710,311$ & $0.0 \%$ \\
\hline
\end{tabular}

Notes: Green "E”: eligible. Yellow “T”: transition funding. Red "G”: graduated. 


\section{Appendix 6b: Projected Global Fund TB Transitions 2015-2040-Universal Progress Scenario}

\begin{tabular}{|c|c|c|c|c|c|c|c|c|c|}
\hline & 岀 & 尺્ત & $\stackrel{\stackrel{\sim}{N}}{\stackrel{N}{N}}$ & ஜ & 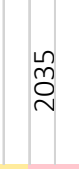 & ণ্ণ & Annual Total & GGHE-D (2015) & $\begin{array}{c}\text { Annual } \\
\text { Allocation as } \\
\% \text { of GGHE-D } \\
\text { (2015) }\end{array}$ \\
\hline Lao P.D.R. & \multicolumn{6}{|c|}{ EEEEEEEEEEEEETTTGGGGGG } & $2,464,383$ & $\$ 142,152,772$ & $1.7 \%$ \\
\hline Nigeria & \multicolumn{6}{|c|}{ EEEEEEEEEEEEEETTTGGGGGG } & $\$ 35,831,717$ & $\$ 2,833,856,844$ & $1.3 \%$ \\
\hline Armenia & \multicolumn{6}{|c|}{ E E E E T T T GGGGGGGGGGGGGGGGG } & $1,046,308$ & $\$ 170,320,559$ & $0.6 \%$ \\
\hline Georgia & \multicolumn{6}{|c|}{ EEEEEEEEETTTGGGGGGGGGGGG\$ } & $2,391,692$ & $\$ 430,523,213$ & $0.6 \%$ \\
\hline Belize & \multicolumn{6}{|c|}{ 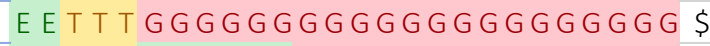 } & 179,276 & $\$ 71,861,319$ & $0.2 \%$ \\
\hline Turkmenistan & \multicolumn{6}{|c|}{ E ETTTEEEEEGGGGGGGGGGGGGGG \$ } & $1,318,888$ & $\$ 536,237,019$ & $0.2 \%$ \\
\hline Nicaragua & \multicolumn{6}{|c|}{ EEEEEEEEEEEEEETTTGGGGGG\$ } & $1,376,572$ & $\$ 562,577,545$ & $0.2 \%$ \\
\hline Guyana & \multicolumn{6}{|c|}{ EE E EEEEEE T T T GGGGGGGGGGGG\$ } & 166,667 & $\$ 73,704,814$ & $0.2 \%$ \\
\hline Sudan & \multicolumn{6}{|c|}{ EEEEEEETTTGGGGGGGGGGGGGG\$ } & $4,087,350$ & $\$ 1,910,000,045$ & $0.2 \%$ \\
\hline Suriname & \multicolumn{6}{|c|}{ EETTTEEEEETTTGGGGGGGGGGGG\$ } & 329,891 & 586 & $0.2 \%$ \\
\hline Guatemala & \multicolumn{6}{|c|}{ 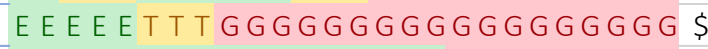 } & $1,949,828$ & $\$ 1,167,666,072$ & $0.2 \%$ \\
\hline Botswana & \multicolumn{6}{|c|}{ EEEEEEEEEEEEEGGGGGGGGG\$ } & 638,824 & $\$ 474,767,842$ & $0.1 \%$ \\
\hline Bolivia & \multicolumn{6}{|c|}{ EEEEEEEEETTTGGGGGGGGGGGG\$ } & $1,882,983$ & $\$ 1,438,991,373$ & $0.1 \%$ \\
\hline Belarus & \multicolumn{6}{|c|}{ EEEEEEEEETTTGGGGGGGGGGGG } & $2,659,314$ & $\$ 2,151,695,480$ & $0.1 \%$ \\
\hline El Salvador & \multicolumn{6}{|c|}{ E E E E T T T GGGGGGGGGGGGGGGGG \$ } & $1,414,247$ & 3,773 & $0.1 \%$ \\
\hline Dominican R & \multicolumn{6}{|c|}{ CE ETTTEEEEETTTGGGGGGGGGGGG\$ } & $1,497,947$ & $\$ 1,710,026,877$ & $0.1 \%$ \\
\hline Paraguay & \multicolumn{6}{|c|}{ 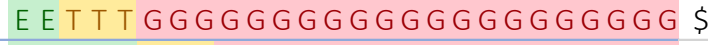 } & 971,774 & $\$ 1,142,133,562$ & $0.1 \%$ \\
\hline Sri Lanka & \multicolumn{6}{|c|}{ E E E E T T T GGGGGGGGGGGGGGGGGG \$ } & $1,008,024$ & $\$ 1,284,378,681$ & $0.1 \%$ \\
\hline Kazakhstan & \multicolumn{6}{|c|}{ E E E EEEEEEGGGGGGGGGGGGGGG\$ } & $3,280,147$ & $\$ 4,305,796,719$ & $0.1 \%$ \\
\hline Albania & \multicolumn{6}{|c|}{ E E T T T GGGGGGGGGGGGGGGGGGGG\$ } & 166,667 & $\$ 327,294,947$ & $0.1 \%$ \\
\hline Peru & \multicolumn{6}{|c|}{ EEEEEEEEEEEEEEEEEEEGGG\$ } & $2,399,764$ & $\$ 6,146,248,203$ & $0.0 \%$ \\
\hline Thailand & \multicolumn{6}{|c|}{ EEEEEEEEEEEEEEEEEEEGGG\$ } & $4,365,503$ & $\$ 11,531,731,877$ & $0.0 \%$ \\
\hline Morocco & \multicolumn{6}{|c|}{ E EEEEEEEETTTGGGGGGGGGGGG\$ } & 779,713 & $\$ 2,421,699,536$ & $0.0 \%$ \\
\hline Romania & \multicolumn{6}{|c|}{ E E E E E E EGGGGGGGGGGGGGGGGG ? } & $1,688,738$ & $\$ 6,853,717,086$ & $0.0 \%$ \\
\hline Panama & \multicolumn{6}{|c|}{ 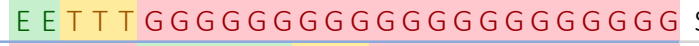 } & 302,169 & $\$ 2,250,173,008$ & $0.0 \%$ \\
\hline Ecuador & \multicolumn{7}{|c|}{ G G G G E E E E E T T T G G G G G G G G G G } & $\$ 4,212,918,270$ & $0.0 \%$ \\
\hline Fiji & \multicolumn{7}{|c|}{ T T G G GEEEEETTTGGGGGGGGGGGG } & $\$ 98,257,777$ & $0.0 \%$ \\
\hline
\end{tabular}

Notes: Green “E”: eligible. Yellow “T”: transition funding. Red “G”: graduated. 